\title{
The Impact of Surface Chemistry on Gold Nanorods Uptake in
}

\section{Stem Cell-derived Therapeutic Cells}

\author{
${ }^{1}$ Grant W. Marquart, ${ }^{2}$ Jonathan Stoddard, ${ }^{2}$ Trevor J. McGill, ${ }^{1}$ Karen Kinnison, ${ }^{1}$ Felica Zhou, \\ ${ }^{3}$ Richard Hugo, ${ }^{2}$ Renee Ryals, ${ }^{2}$ Scott Schubert, and ${ }^{4}$ Marilyn R. Mackiewicz ${ }^{*}$ \\ ${ }^{1}$ Department of Chemistry, Portland State University, Portland, OR 97207 \\ ${ }^{2}$ Oregon National Primate Center, Oregon Health \& Science University, Portland, Oregon 97006 \\ ${ }^{3}$ Department of Geology, Portland State University, Portland, OR 97207 \\ ${ }^{4}$ Department of Chemistry, Oregon State University, Corvallis, OR 97331
}

*To whom correspondence should be addressed. E-mail: marilyn.mackiewicz@oregonstate.edu

\begin{abstract}
Gold nanorods (AuNRs) hold tremendous potential to improve the diagnosis and therapeutic options across the blood-retinal barrier to treat retinal diseases. For clinical ophthalmological translation, a fundamental understanding of how their physicochemical properties such as size, shape, charge, surface chemistry, and concentration, impact their stability biological environments, mechanism and efficiency of uptake, and toxicity is a necessity. Here we interrogated the uptake efficiency, biocompatibility, and stability of two subtypes of AuNRs with different types of surface coatings and varying charges, including a commercially available set of AuNRs with a $5 \mathrm{~nm} \mathrm{mSiO}$-polymer coating and hybrid lipid-coated AuNRs developed in-house. Confocal and bright field microscopy images showed uptake of both subtypes of AuNRs in retinal pigment epithelium (RPE), neural progenitor (NP), and baby hamster kidney (BHK) cells. Transmission electron microscopy (TEM) confirms both types of AuNRs are taken up into the cytoplasm of the cells; however, larger aggregates of AuNRs are observed with the more positive and "sticky" AuNRs with a $5 \mathrm{~nm} \mathrm{mSiO}$-polymer coating than the slightly negative hybrid lipidcoated AuNRs. Inductively Coupled Mass Spectroscopy (ICP-MS) confirm that $\sim 3,000$ of the
\end{abstract}


slightly negative hybrid lipid-coated AuNRs cells and 5,400 of the positively charged AuNRs with a $5 \mathrm{~nm} \mathrm{mSiO}$-polymer coating $(+35 \mathrm{mV})$ are taken up into RPE and BHK cell lines. Stability studies in a variety of cellular media showed that hybrid lipid-coated AuNRs are stable and disaggregated in water, $10 \mathrm{mM}$ PBS buffer $\mathrm{pH}$ 7, and BHK media except for NP media. In contrast, the positively charged AuNRs with a $5 \mathrm{~nm} \mathrm{mSiO}$-zeta polymer coating aggregated in all media, indicating more interactions with each other and components of the media. Bright-field and TEM confirm the presence of large aggregates of AuNRs on the surface and within the cytoplasm. Cytotoxicity studies both subtypes of AuNRs have an $80 \pm 8 \%$ cell viability, indicating mild toxicity. The hybrid lipid-coated AuNR with the cell-penetrating peptide had the least toxicological impact with a >92 $\pm 7 \%$ cell viability. Our study highlights the importance of evaluating the impact of the physicochemical features of each new nanoparticle design on their stability in biologically relevant environments and their impact on cellular uptake and toxicity in stem cell-derived therapeutic cells. Here we also provide a simple design strategy for tuning the surface chemistry of robust hybrid lipid-coated AuNRs to enhance cellular uptake to label stem cells with minimal aggregation and toxicity.

KEYWORDS. Lipid-coated gold nanorods, optical imaging, stem cells, cell-penetrating peptides, cell uptake studies, toxicity

\section{INTRODUCTION}

The exploitation of nanotechnologies for modern medicine is still on a steep upward trajectory towards clinical translation as new materials with novel properties are discovered and as we gain a better understanding of how these materials interface and behave with biological systems. ${ }^{1-10} \mathrm{~A}$ range of nanomaterials are sought for use as drug delivery, imaging, cell labeling, and targeting 
agents or as biological sensors for several disease areas, which include cancer, cardiovascular disease, Alzheimer's, and more recently COVID-19. The potential use of nanomaterials in the field of ophthalmology is also gaining traction as these have the power to improve the safety and efficacy of current therapies or surgical intervention ${ }^{11}$ and improve the diagnoses of retinal diseases such as retinitis pigmentosa, age-related macular degeneration, glaucoma, and retinal neovascularization. ${ }^{12}$

Thus far, most of the nanomaterials developed ophthalmology applications have been amphiphilic molecules, metals, or polymers. ${ }^{12}$ Polymeric nanoparticles are typically comprised of polyamidoamine (PAMAM), poly-lactic acid (PLA), poly-lactic-co-glycolic acid (PLGA), and polyglycolic acid (PGA) $)^{13-18}$ while amphiphilic molecules are in the form of liposomes ${ }^{19-21}$ and have been used drug delivery agents. Metal-nanoparticles such as silver and gold have also been used as antiangiogenic agents in retinal diseases such as $\mathrm{AMD}^{10,22-23}$ These types of nanomaterialbased delivery systems have increased the bioavailability of drugs, improved the rate of drug release, and reduced dosing or injection frequency compared to traditional methods for retinal diseases such as diabetic retinopathy, which require a series of intravitreal injections with antivascular endothelial growth factor (VEGF) antibodies. ${ }^{24-28}$ Therefore, the construction of safe nanomaterials with features and properties that allow them to cross the blood-retinal barrier (BRB) for delivery of topical application or intraocular injections is of significant interest.

Another important area where nanotechnologies a growing in importance in ophthalmology and medicine is cell-based regenerative therapies (RMTs), which hold enormous potential for a variety of incurable diseases including kidney, ${ }^{29}$ liver, ${ }^{30}$ diabetes ${ }^{31}$, and retinal degeneration. ${ }^{32}$ The slow translation of RMTs in retinal cell-transplantation therapy, from bed to bench side is hindered by the lack of convincing data regarding their safety and efficacy in preclinical models before 
applying those therapies to humans. Current methods for evaluating cell-based therapies rely on histological analysis of tissues post-mortem. This approach requires many animals to be sacrificed at multiple time points to gain insight into cell migration and integration after transplantation. Therefore, alternative strategies for visually tracking stem cells are crucial. Recent studies show that nanomaterials can be used for labeling stem cells for in vivo tracking using imaging technologies such as X-ray, fluorescence, and optical coherence tomography (OCT) imaging. ${ }^{33-34}$ Although many contrast agents are well established for various imaging modalities, ${ }^{35-36}{ }^{37-39}$ to date there is still a limited number of well-defined nanomaterials for OCT imaging or stem cell labeling, which are at the laboratory development stage. ${ }^{40}$ These include carbon nanotubes, ${ }^{41}$ magnetic nanoparticles, ${ }^{42}$ and silicon nanoparticles, ${ }^{43}$ which mostly operate in the NIR-I window $(650-950 \mathrm{~nm})$ with small scattering cross-sections in the NIR-II window (1000-1700 nm). Hence, recent efforts are focused on developing contrast agents that operate in the NIR-II window for OCT for imaging at the micron-scale resolution. Gold nanoparticles (AuNPs) are of particular interest for OCT because they have strong localized surface plasmon resonance (LSPR) for interaction with light ${ }^{44}$ and can be tuned towards the NIR-I and NIR-II windows. ${ }^{45-46}$ Studies show that the size and shape of AuNPs, nanospheres, ${ }^{47-48}$ nanocages, nanoshells, ${ }^{49-51}$ nanobipyramids, ${ }^{40}$ branched AuNPs,${ }^{52}$ nanoprisms,${ }^{53}$ nanorods,${ }^{54-59}$ and nanodisks, ${ }^{60}$ have high scattering efficiencies and OCT contrast when the SPR band is within the central operating wavelength of the OCT. ${ }^{61-62}$ Silver nanoparticles (AgNPs), ${ }^{63}$ silica-coated gold nanostars, ${ }^{64}$ silica-coated silver nanorods (AgNRs), ${ }^{65-66}$ and titanium oxide $\left(\mathrm{TiO}_{2}\right)^{67}$ also have high scattering efficiencies. For cell labeling studies nanomaterials such as quantum dots, ${ }^{68}$ luminescent nanoparticles, ${ }^{69}$ iron oxide nanoparticles, ${ }^{70}$, and AuNPs ${ }^{71-72}$ have been employed as they produce intense signal sensitivity to detect a low number of cells with a distinct advantage over reporter genes. ${ }^{40}$ However, all labeling probes suffer from signal dilution during cell division or probe leakage making it difficult to track 
the cells long-term. ${ }^{40}$ To overcome this challenge researchers are selecting and exploiting proteins such as epidermal growth factor receptor ${ }^{73}$ or HER-2 $2^{74}$ and targeting peptides to enhance uptake and targeting of cells or subcellular organelles ${ }^{75}$ To advance cell-based therapies, new designs of nanomaterials will be forthcoming and there is an unmet need to understand how the physicochemical properties of the nanomaterials influence nanoparticle uptake and performance inside the cell without altering its function and inducing toxicity or an immune response.

With the limited amount of nanomaterial-based OCT contrast and cell-labeling agents available for tracking cell-based therapies, there are still few systematic studies of nanoparticlecell interactions that enable us to understand how the physicochemical features (size, shape, surface charge, surface ligands) dictate their stability, uptake efficiency, nanoparticle-biological interactions, and toxicity in ocular environments or retinal cells. ${ }^{76,77}$ Regardless, numerous studies show that the physicochemical properties significantly dictate the stability of nanoparticles, their circulation time, the efficiency of cellular internalization, mechanism of uptake, clearance, and relative toxicity in vitro and in vivo. ${ }^{78-80,81-86}$ For example, studies have shown that a surface charge plays a role in nanoparticle-biological interactions and cellular uptake of nanoparticles. ${ }^{87-96}$ Nanoparticles with a positive charge are known to enhance cellular uptake to improve the efficacy of imaging, gene transfer, and drug delivery. ${ }^{97}$ Consequently, positively charged nanoparticles have also been shown to have higher toxicity. ${ }^{98-99}$ In contrast, other studies show that the cationic charge can be masked with serum proteins that bind to the surface and minimize toxicity. ${ }^{100}$ The formation of a protein corona on the nanoparticle surface plays a pivotal role in nanoparticle interactions, mechanism of uptake and efficiency, and toxicity with biological systems. ${ }^{52,57-59}$ 101${ }^{105}$ Since these physicochemical features have the power to dictate the behavior and properties of nanomaterials it is important to understand how these properties of each new nanoparticle type 
influence their mechanism of uptake, efficiency, and any potential adverse effects on therapeutic stem cells that would be placed in a living eye.

Here we describe the synthesis and study of two subtypes of AuNRs that absorb in the NIR-II region with two different surface coatings to evaluate their cellular uptake, nanoparticleinteractions, and toxicity in different cell lines, which include retinal pigment epithelium (RPE) and neuronal progenitor cell (NP) cells. Previously we showed that lipid-membranes anchored by long-chained hydrophobic thiols are biocompatible coatings that can stabilize gold nanoparticles $(\mathrm{AuNPs})^{106-110}$ and silver nanoparticles (AgNPs) of various sizes and shapes that do not undergo membrane rearrangement, unlike traditional liposomes. ${ }^{111-112}$ Furthermore, the hybrid lipid-coated AuNPs and AgNPs show minimal to no toxicity in vivo and instability under harsh biological environments. ${ }^{111,113}$ Hence, this coating strategy is expected to produce safe AuNRs with minimal toxicity to stem cell-derived therapeutic cells. We compared the effect of the hybrid lipid-coated AuNRs (Scheme 1, A) to a commercially set of AuNRs with $5 \mathrm{~nm}$ mesoporous silicon shell coated with a proprietary polymer (Scheme 1, B) reported to enhance cellular uptake. Confocal and bright-field microscopy were used to examine the stability of the coated-AuNRs in biological media, their cellular uptake efficiency, and cellular toxicity was compared. Inductively coupled Mass Spectroscopy (ICP-MS) and Transmission Electron Microscopy (TEM) was used to quantify the amount of AuNRs taken up and their localization in cells. Our studies show that the coatings have a profound effect on AuNR stability, cellular uptake efficiency, and biocompatibility with stem cell-derived therapeutic cells. 
Scheme 1. Cartoon of Gold Nanorods with Hybrid Lipid Membrane or $5 \mathrm{~nm} \mathrm{mSiO} 2$ and Polymer Layer

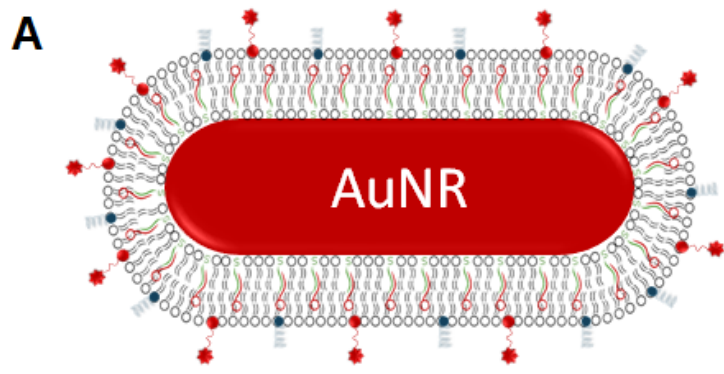

Hybrid Lipid-coated AuNRs

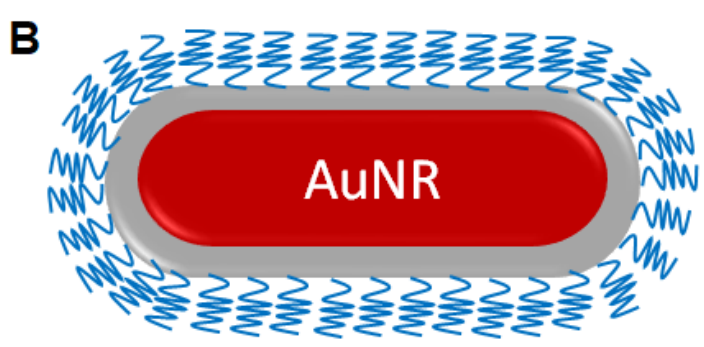

AuNRs $-\mathrm{mSiO}_{2}$ with polymer layer

\begin{tabular}{|c|c|}
\hline Components & Key \\
\hline L- $\alpha$-phosphatidylcholine (PC) & $=$ \\
\hline Phosphatidylethanolamine-lissamine Rhodamine B (PE-LRSH) & Zeta polymer \\
\hline Phosphatidylethanolamine-GRKKRRQRR (PE-RGD) & Sodium oleate (SOA) \\
\hline $\begin{array}{c}\text { Hexanethiol (HT) } \\
\text { (DOTAP) }\end{array}$ \\
\hline $\begin{array}{c}\text { 1,2-di-(9Z-octadecenoyl)-3-trimethylammonium-propane chloride } \\
\text { (DOT }\end{array}$ \\
\hline
\end{tabular}

\section{Materials and Methods}

Reagents. Aqueous solutions of gold citrate-capped nanorods (69 nm x $12 \mathrm{~nm}$ ) were from NanoComposix.com, and gold $\mathrm{mSiO}_{2}$-capped nanorods with zeta polymer (55 nm x $10 \mathrm{~nm}$ or 96 $\mathrm{nm}$ x $25 \mathrm{~nm}$ ) were purchased from Nanopartz.com Sodium oleate was from TCI America, while 1,2-distearoyl-sn-glycero-3-phosphoethanolamine-N-[4-(p-(cysarginylglycylaspartate-

maleimidomethyl)cyclohexane-carboxamide] (PE-RGD), 1,2-dioleoyl-3-trimethylammoniumpropane (DOTAP), and 1,2-dioleoyl-sn-glycero-3-phosphoethanolamine-N-(lissamine rhodamine B sulfonyl) (PE-LRSH) were purchased from Avanti Polar Lipids. Cetyltrimethylammonium bromide (CTAB), 95\% L- $\alpha$-phosphatidylcholine (PC), TWEEN $® 20$, and 95\% 1-hexanethiol (HT) were purchased from Sigma Aldrich. Sodium phosphate monobasic monohydrate and sodium 
phosphate dibasic heptahydrate were from BDH Chemicals. Potassium cyanide (KCN) and chloroform were from Mallinckrodt. Methanol was from OmniSolv. Nanopure water was from a Milli-Q ultra-pure system. Baby hamster kidney (BHK) (ATCC), neural progenitor cells (NP) (Stem Cell Technologies ${ }^{\mathrm{TM}}$ ), and retinal pigment epithelial (RPE) cell lines generated at the Oregon National Primate Center were used for cell culture studies. All other reagents were used as received.

Liposome Preparation. Thin films comprised of a 9:1 ratio of PC:PE-LRSH (45 $\mu \mathrm{L}$ of $21.6 \mathrm{mM}$ PC and $285 \mu \mathrm{L}$ of $379 \mu \mathrm{M}$ PE-LRSH in $\mathrm{CHCl}_{3}$ ), 6:3:1 ratio of PC:PE-LRSH:DOTAP or PC:PELRSH:CTAB (30 $\mu \mathrm{L}$ of $21.6 \mathrm{mM}$ PC, $285 \mu \mathrm{L}$ of $379 \mu \mathrm{M}$ PE-LRSH, $27 \mu \mathrm{L}$ of $11.9 \mathrm{mM}$ DOTAP, or $35 \mu \mathrm{L}$ of $9.15 \mathrm{mM} \mathrm{CTAB}$ in $\left.\mathrm{CHCl}_{3}\right), 8: 1: 1$ ratio of PC:RGD:PE-LRSH ( $40 \mu \mathrm{L}$ of $21.6 \mathrm{mM} \mathrm{PC}$, $157 \mu \mathrm{L}$ of $171 \mu \mathrm{M}$ RGD in methanol, and $285 \mu \mathrm{L}$ of $379 \mu \mathrm{M}$ PE-LRSH in $\mathrm{CHCl}_{3}$ ), or 7:1:1:1 ratio of PC:RGD:PE-LRSH:DOTAP (35 $\mu \mathrm{L}$ of $21.6 \mathrm{mM}$ PC, $157 \mu \mathrm{L}$ of $171 \mu \mathrm{M}$ RGD in methanol, 285 $\mu \mathrm{L}$ of $379 \mu \mathrm{M}$ PE-LRSH, and $9 \mu \mathrm{L}$ of $11.9 \mathrm{mM}$ DOTAP in $\mathrm{CHCl}_{3}$ ) were prepared by solvent evaporation under $\mathrm{N}_{2}$ gas. The total number of moles of lipids in each film was $1.08 \mu$ mol. Following $\mathrm{N}_{2}$ evaporation the thin films were dried under vacuum for $12 \mathrm{~h}$ before the addition of $2 \mathrm{~mL}$ of $10 \mathrm{mM}$ sodium phosphate buffer at $\mathrm{pH}$ 8.0. The film was vigorously shaken to resuspend the lipids followed by sonication for 90 min until the cloudy solution turned transparent.

Preparation of hybrid lipid-coated AuNRs. Sodium oleate (SOA) $\left(2.2 \mu \mathrm{L}\right.$ of $9.3 \mathrm{mM}$ in $\mathrm{H}_{2} \mathrm{O}$ ) was added to $1 \mathrm{~mL}$ of AuNRs with an optical density (OD) of 1.1 in $\mathrm{H}_{2} \mathrm{O}$ and stirred for $20 \mathrm{~min}$. To the AuNR-SOA solution, $7.4 \mu \mathrm{L}$ of $0.54 \mathrm{mM}$ of the liposome solution was added and then incubated for $40 \mathrm{~min}$. This was followed by the addition of $0.2 \mu \mathrm{L}$ of $5 \mathrm{mM}$ hexanethiol (HT) in ethanol that was stirred for $30 \mathrm{~min}$. The resulting hybrid lipid-coated AuNRs were buffered with 
$10 \mu \mathrm{L}$ of $1 \mathrm{M}$ sodium phosphate buffer at $\mathrm{pH}$ 8.0. To purify the hybrid lipid-coated AuNRs, the sample was incubated with $10 \mu \mathrm{L}$ of $10 \mathrm{mM}$ TWEEN $\circledast 20$ for $20 \mathrm{~min}$ at $25{ }^{\circ} \mathrm{C}$ to disrupt and destabilize any "nanoparticle-free" liposomes. A Thermo Scientific Sorvall ST 40R at $4700 \mathrm{rpm}$ using GE Healthcare ultracentrifuge concentrators with a PES membrane (Vivaspin 20, MWCO = $10 \mathrm{kDa}$ ) for 10 rounds at 4 min each were used to remove free lipids, sodium oleate, and thiol. The final hybrid AuNR-SOA-Liposome-HT was resuspended in $10 \mathrm{mM}$ sodium phosphate buffer at $\mathrm{pH} 8.0$.

Stability Studies. To determine if the AuNRs are completely covered by the hybrid lipid membrane, the AuNR-SOA-Liposome-HT were exposed to $\mathrm{KCN}\left(20 \mu \mathrm{L}\right.$ of $307 \mathrm{mM}$ in $\left.\mathrm{H}_{2} \mathrm{O}\right)$ at a final concentration of $6 \mathrm{mM}$ for $24 \mathrm{~h}$. The percent change in the $\lambda_{\max }$ and absorbance was monitored with UV-Vis to assess the hybrid AuNR membrane stability. For stability studies, AuNRs were incubated at $5 \times 10^{\wedge} 10 \mathrm{AuNRs} / \mathrm{ml}$ in either BHK and RPE cell culture media (DMEM, 10\% fetal bovine serum (FBS), and 1\% Penicillin Streptomycin (PS)), water, 1\% PBS pH 7.4, or serum-free NP media. Following $24 \mathrm{~h}$ at $37^{\circ} \mathrm{C}$, samples were imaged using brightfield microscopy.

Optical Measurements and Fluorescence Imaging. UV-vis spectra were recorded on a Shimadzu UV-3600 UV-vis-NIR spectrophotometers using a $1 \mathrm{~cm}$ quartz cuvette. Fluorescence measurements were conducted on samples containing the LRSH fluorophore using a PTI spectrophotometer with Felix32 software with a quartz cuvette at an excitation of $568 \mathrm{~nm}$ and an emission of $580 \mathrm{~nm}$ to check for free dye after purification. For evaluation of the AuNR uptake into the cells, a Leica TCS SP5 Confocal Microscope with fluorescence and bright-field imaging was used. 
Transmission Electron Microscopy (TEM). For TEM imaging, 500,000 BHK cells were plated into 24-well culture plates and treated with $5 \times 10^{5}$ AuNR, \#8, 9, 0, and 1 untreated well for $24 \mathrm{~h}$. Cells were washed $3 \mathrm{x}$ with $1 \mathrm{x} 10 \mathrm{mM}$ PBS pH 7.4, dissociated with $0.25 \%$ trypsin, centrifuged, and fixed with 4\% PFA. For visualization of nanoparticle uptake in cells, specimens were prepared via microwave fixation and traditional embedding in Eponate 12 (Ted Pella; Redding CA). Fixation, dehydration, and resin infiltration were conducted in a BioWave microwave processor (Ted Pella Inc., Redding CA). Specimens were fixed in 3\% glutaraldehyde buffered with $0.1 \mathrm{M}$ cacodylate, post-fixed in $1 \%$ osmium tetroxide buffered with $0.1 \mathrm{M}$ cacodylate. Samples were then dehydrated in a graded water/acetone series, resin-infiltrated in a graded acetone/resin series, and cured overnight in a $60{ }^{\circ} \mathrm{C}$ oven. After ultrathin sectioning to $<100 \mathrm{~nm}$, one split of samples was left unstained to minimize contrast due to staining and maximize contrast due to the presence of metal nanoparticles. The second split of ultrathin specimens was stained using standard protocols (Dykstra 1993) for uranyl acetate and lead citrate to allow for typical ultrastructural imaging. Ultrathin section ribbons were floated onto carbon-coated ( $300 \AA$ ) Formvar films on copper grids from Ted Pella. Transmission electron micrographs were acquired on a Tecnai F-20 FEI microscope using a CCD detector, at an acceleration voltage of $200 \mathrm{kV}$. Images were analyzed using ImageJ Software.

Cell Culture and AuNR Uptake Studies. BHK and RPE cell lines were cultured in Dulbecco's Modified Eagle Medium (DMEM) with $10 \% \mathrm{FBS}$ and $1 \% \mathrm{PS}$ at $37{ }^{\circ} \mathrm{C}$ in a humidified $5 \% \mathrm{CO}_{2}$ atmosphere, while the NP cell lines were cultured in STEMdiff ${ }^{\mathrm{TM}}$ medium. To evaluate cell uptake, 150,000 cells were seeded into each well of a 4-well chamber slide (Lab-Tek $\left.{ }^{\circledR}\right)$. After $24 \mathrm{~h}$ incubation, the culture medium was replaced with a fresh medium containing the different AuNR samples with concentrations ranging from $1.6 \times 10^{9}$ to $4.0 \times 10^{12} \mathrm{AuNRs} / \mathrm{mL}$ depending on the 
study herein. After the cells were further incubated for $24 \mathrm{~h}$, they were washed 3 times with $1 \%$ PBS buffer pH 7.4 to remove any AuNRs adsorbed on the cell surface. The cells were subsequently fixed for 5 min using 4\% paraformaldehyde (Sigma-Aldrich) to evaluate AuNR uptake in the varying cell lines using a Leica confocal microscope under fluorescence and bright field.

MTS Assay. To determine cytotoxic effects of AuNR uptake, the viability of cells after AuNR uptake was compared. Ten thousand BHK cells were seeded into each well on a 96 well-plate and incubated for $24 \mathrm{~h}$ in medium (DMEM with 5\% FBS) that is replaced with a fresh medium containing the AuNRs \#1, \#3, \#8, \#9, and \#10 (Table 1) at three concentrations of each AuNR type $\left(1.0 \times 10^{8}, 1.0 \times 10^{9}\right.$, and $\left.1.0 \times 10^{10}\right)$ in each well. After $24 \mathrm{~h}$ of incubation, the cells were washed with DPBS and fresh medium $(100 \mu \mathrm{L})$ was added to each well. MTS solution (20 $\mu \mathrm{L})$ was subsequently added to each well and after $3 \mathrm{~h}$ of incubation, absorbance was measured using a Spectramax M5 multi-mode plate reader at $490 \mathrm{~nm}$. A well with only media and $20 \mu \mathrm{L}$ of MTS solution was used to determine and subtract out background noise from the readings. The cell viability (\%) for each nanoparticle type relative to control was calculated.

Determination of Intracellular Uptake of AuNRs by ICP-MS. For quantitative determination of AuNR uptake, BHK and RPE cell lines were cultured in 6-well plates (Corning). When the cells reached $80 \%$ confluence, the culture medium was replaced with fresh DMEM containing the AuNR samples at a concentration of $5 \times 10^{10} \mathrm{AuNRs} / \mathrm{mL}$ at $37^{\circ} \mathrm{C}$. After $24 \mathrm{~h}$ of incubation, the samples were collected in a centrifuge tube and washed 3 times with $1 \%$ PBS buffer $\mathrm{pH} 7.4$ by centrifugation at $200 \mathrm{~g}$ for $5 \mathrm{~min}$ and then frozen until ICP-Analysis. The frozen cell pellets were submitted to the Elemental Analysis Core at Oregon Health and Science University (OHSU) to determine the concentration of Au. Samples were digested directly in the provided centrifuge tubed 
by adding $100 \mu \mathrm{L}$ aqua regia ( $75 \mu \mathrm{L} \mathrm{HCl}$ (trace metal grade, Fisher) and $25 \mu \mathrm{L} \mathrm{HNO}_{3}$ (trace metal grade, Fisher)) to each cell pellet and briefly heating them to $90^{\circ} \mathrm{C}$ for $45 \mathrm{~min}$. Samples were cooled down to ambient temperature and digestion was continued at room temperature overnight. The samples were then diluted with $1 \% \mathrm{HCl}$ (trace metal grade, Fisher) containing $1 \%$ cysteine to a total volume of $1 \mathrm{~mL}$. Samples were vortexed to check for complete digestion after dilution. For ICP-MS measurements were further diluted with $1 \%$ cysteine in $1 \% \mathrm{HCl}$ into $15 \mathrm{~mL}$ metalfree polypropylene tubes. ICP-MS analysis was performed using an Agilent 7700x equipped with an ASX 500 autosampler. The system was operated at a radio frequency power of 1550W, an $\mathrm{Ar}$ plasma gas flow rate of $15 \mathrm{~L} / \mathrm{min}$, and an Ar carrier gas flow rate of $0.9 \mathrm{~L} / \mathrm{min}$. Au was measured in NoGas mode. Data were quantified using a 10 -point $(0,0.05,0.1,0.2,0.5,1,5,10,50) \mathrm{ppb}$ $(\mu \mathrm{g} / \mathrm{kg}))$ calibration curve. For each sample, data were acquired in triplicates and averaged. A coefficient of variance $(\mathrm{CoV})$ was determined from frequent measurements of a sample containing $10 \mathrm{ppb} \mathrm{Au}$. An internal standard (Sc, Ge, Bi) continuously introduced with the sample was used to correct for detector fluctuations and to monitor plasma stability.

Statistical Analysis. Data were expressed as means and stanRdard errors. Statistical significance was determined using analysis of variance or t-test. $\mathrm{P}<0.5$ was considered statistically significant. 
Table 1. Physical Properties of hybrid lipid-coated AuNRs and commercially available AuNRs with $\mathrm{a} \mathrm{mSiO}_{2}$ and polymer layer

\begin{tabular}{|c|c|c|c|c|c|}
\hline AuNR ID & Coating & Dye & $\lambda_{\max }(\mathrm{nm})$ & Size (nm) & Zeta Potential (mV) \\
\hline$\# 1$ & $\mathrm{mSiO}_{2} /$ Polymer & $\mathrm{Cy} 3$ & 950 & $55 \times 10$ & +5 \\
\hline$\# 2$ & $\mathrm{mSiO}_{2} /$ Polymer & LRSH & 900 & $96 \times 25$ & +8 \\
\hline$\# 3$ & $\mathrm{mSiO}_{2} /$ Polymer & LRSH & 925 & $96 \times 25$ & +30 \\
\hline$\# 4$ & $\mathrm{mSiO}_{2} /$ Polymer & LRSH & 900 & $96 \times 25$ & +35 \\
\hline$\# 5$ & $\mathrm{mSiO}_{2} /$ Polymer & LRSH & 900 & $96 \times 25$ & +50 \\
\hline$\# 6$ & PC:PE-LRSH (9:1) & LRSH & 980 & $69 \times 12$ & $\mathrm{~N} / \mathrm{A}$ \\
\hline$\# 7$ & PC:PE-LRSH:CTAB (6:1:3) & LRSH & 980 & $69 \times 12$ & N/A \\
\hline$\# 8$ & PC:PE-LRSH:DOTAP (6:1:3) & LRSH & 980 & $69 \times 12$ & -7.3 \\
\hline$\# 9$ & PC:PE-RGD:PE-LRSH (8:1:1) & LRSH & 980 & $69 \times 12$ & -4.8 \\
\hline$\# 10$ & PC:PE-RGD:PE-LRSH:DOTAP (7:1:1:1) & LRSH & 980 & $69 \times 12$ & -6.6 \\
\hline
\end{tabular}

\section{RESULTS AND DISCUSSION}

\section{Gold Nanorods (AuNRs) with Modified Surface Coatings}

In this study, AuNRs with a variety of coatings were prepared to study the effects of surface chemistry on cellular uptake and toxicity. One subtype of AuNRs with a $\mathrm{mSiO}_{2}$ layer and a proprietary polymer was purchased from Nanopartiz.com, while the other subtype was prepared in-house with a lipid membrane anchored to the AuNR core with hexanethiol (HT) that was assembled through a layer-by-layer approach (Scheme 1). Briefly, sodium oleate (SOA) was added to a $1 \mathrm{~mL}$ aqueous solution of minimally citrate-capped AuNR (1.0 O.D.) for $20 \mathrm{~min}$. The citrate-capped AuNRs were purchased from NanoComposix.com with an average length of 69.7 $\pm 7.3 \mathrm{~nm}$ and width of $12.1 \pm 0.8 \mathrm{~nm}$. The AuNR concentration was $1.8 \times 10^{11}$ AuNRs $/ \mathrm{mL}$ with a zeta potential of $-38.5 \mathrm{mV}$. The AuNR-SOA solution was incubated with preformed liposomes for 40 min before the addition of HT. The AuNR-SOA-lipid-HT solution was then incubated for a 
minimum of 30 min to ensure the membrane was tightly packed and completely covering the AuNR surface. A minimal amount of lipids is used to cover the AuNR surface thereby reducing the "nanoparticle-free" liposomes in the solution. The number of lipids needed to completely coat each AuNR was determined from the number of nanoparticles and the dimensions of the AuNR (See Supporting Information). A variety of liposome formulations with fluorescent dyes, cationic or anionic ligands, and cell-penetrating peptides are used for coating the AuNRs. A fluorophore-labeled lipid, 1,2-dioleoyl-sn-glycero-3-phosphoethanolamine-N-(lissamine rhodamine B sulfonyl) (PE-LRSH), is incorporated for visual confirmation of cellular uptake using confocal fluorescence microscopy. Cetylammonium bromide (CTAB) and 1,2-dioleoyl-3trimethylammonium-propane (DOTAP) are expected to add a positive surface charge to the AuNRs, which is expected to enhance the cellular uptake of the AuNRs compared to neutral or negative charged nanoparticles. DOTAP is a well-known cationic transfection agent that is used to enhance the delivery of liposomes ${ }^{114}$ and liposome-coated ${ }^{115}$ nanomaterials for drug delivery, and although excess CTAB is toxic, only a small amount was integrated into the membrane scaffolding to enhance cellular uptake. Similarly, the lipid-conjugated cell-penetrating peptide, distearoyl-sn-glycero-3-phosphoethanolamine-N-[4-(p-(cysarginylglycylaspartate-

maleimidomethyl)cyclohexane-carboxamide] (PE-RGD), is expected to enhance uptake. After assembly, the hybrid lipid-coated AuNRs were purified by ultracentrifugation before their use in cell culture studies to remove any excess lipids, thiol, dye-conjugated lipids, or SOA. It is important to remove any excess fluorescent dye from the solution after synthesis to avoid their confounding effects on the tracking of hybrid-lipid-coated AuNRs with liposome formulations containing PE-LRSH. Fluorescence spectra were taken of fluorescent-labeled hybrid lipid-coated AuNRs and the filtrate before and after purification to confirm that the hybrid AuNR solutions contained no free PE-LRSH dye. 
The addition of a hybrid lipid-membrane to the AuNR does not change the optical properties of the AuNR as no significant shift in the localized surface plasmon resonance (LSPR) band is observed. The zeta potential measurements for all purified hybrid lipid-coated AuNRs and commercially purchased AuNRs used in this study are reported in Table 1. The $\mathrm{mSiO}_{2} /$ polymercoated AuNRs all had a positive surface charge varying from $+5 \mathrm{mV}$ to $+50 \mathrm{mV}$, while the hybrid lipid-coated AuNRs have a slightly negative zeta potential is at -5 to $-7 \mathrm{mV}$ even when cationic ligands such as DOTAP incorporated into the platform. The DOTAP, CTAB, PE-LRSH, and PC ligands have an overall neutral or positive charge, therefore the slight negative charge comes from the SOA molecules incorporated into the AuNR platform since the ratio of lipids:SOA:HT is 4:2:1 where there is a greater amount of SOA than ligands with cationic charges.

Previous studies show that hybrid lipid-coated AuNPs and AgNPs are resistant to strong oxidants only when the membrane is tightly packed around the nanoparticle surface. ${ }^{106-107,} 116$ Therefore, to ensure that the AuNRs are completely covered by an intact hybrid bilayer, potassium cyanide (KCN) a well-known etchant, is added to every batch of hybrid-lipid coated AuNRs prepared. Briefly, a 700-fold excess of KCN was added to $1 \mathrm{~mL}$ hybrid-lipid coated AuNRs (1.1 O.D.), and the LSPR band at $\lambda_{\max } 980 \mathrm{~nm}$ was monitored over $24 \mathrm{~h}$ (Figure 1). No shift in the $\lambda_{\max }$ or change in the O.D. was observed before (Figure 1, (i)) or after $24 \mathrm{~h}$ incubation with $\mathrm{CN}$ - (Figure 1, (ii)). This indicates that the AuNRs were completely covered with a tightly packed membrane arrangement and are consistent with what was previously observed. ${ }^{106-107}$ Similarly, when citratecapped AuNRs without a hybrid lipid-coating are exposed to $\mathrm{CN}$ - there is a rapid change in color from red to colorless within seconds and disappearance of the LSPR band (Figure S1). Hybrid lipid-coated AuNRs that are completely shielded and that are stable in the presence of strong oxidants are expected to have minimal interactions with biomolecules that could destabilize the nanoparticles in vitro or in vivo by undergoing ligand exchange with the lipids or by binding 
directly with the gold surface. Consequently, these hybrid lipid-coated AuNRs are less likely to induce toxicity.

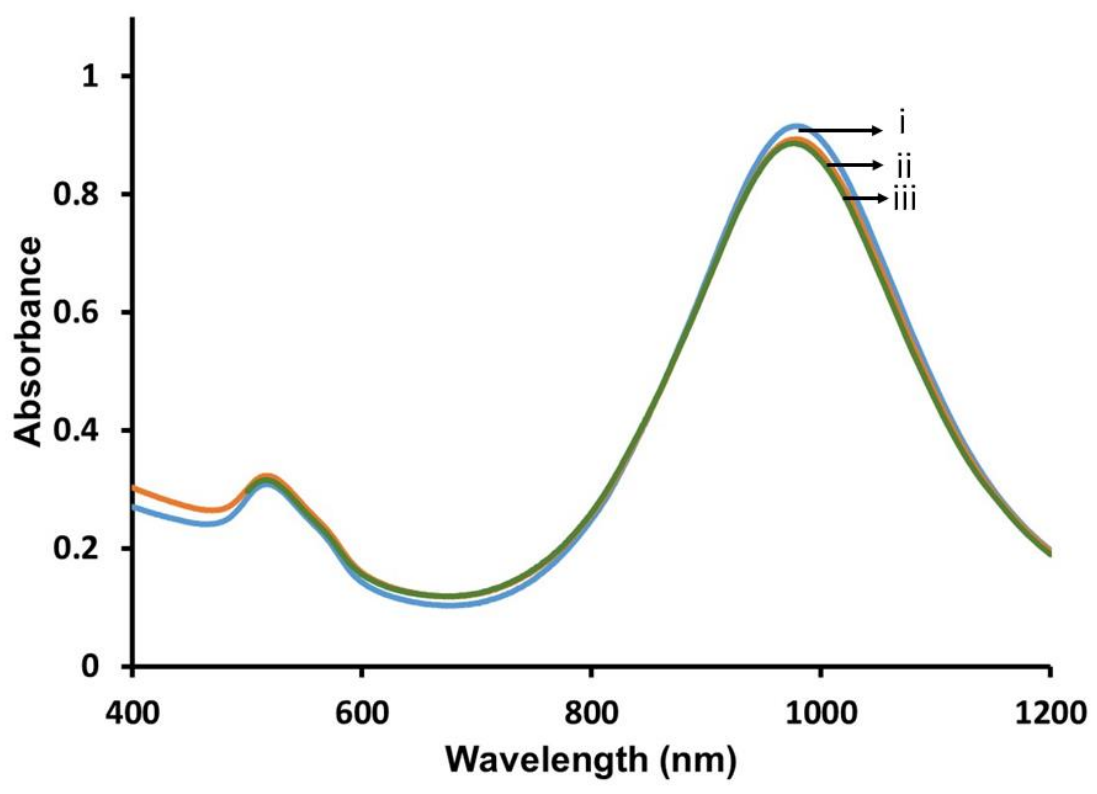

Figure 1. A) Representative UV-Vis Spectra of $1 \mathrm{~mL}$ AuNR-PC:PE-LRSH:DOTAP (6:1:3) i) before and ii) after $1 \mathrm{~h}$, and iii) $24 \mathrm{~h}$ incubation with $20 \mu \mathrm{L} 307 \mathrm{mM} \mathrm{KCN}$. All samples were in $10 \mathrm{mM}$ sodium phosphate buffer $\mathrm{pH}$ 8.0.

\section{Cellular Uptake Studies of Lipid-Coated Hybrid AuNRs}

Before AuNRs can be employed in ophthalmology applications as a diagnostic or therapeutic agent, it is necessary to evaluate their uptake in cells and potential toxicity. An increasing number of studies during the last decade show that the physicochemical properties of nanomaterials, size, shape, ${ }^{117}$ surface chemistry, ${ }^{118-120}$ and charge,${ }^{121-123}$ influence their cellular uptake, which is also dependent on the cell type. ${ }^{124-126}$ Therefore, it is important to screen each new type of nanomaterial and its impact on cellular uptake and toxicity. Here a comparative study of a variety of hybrid-lipid coated AuNRs and the commercially purchased AuNRs with the $\mathrm{mSiO}_{2}$ layer and proprietary polymer was carried out to evaluate how the surface coatings and their charge influence their efficiency of uptake, biocompatibility, and localization in Baby hamster kidney 
cells (BHK), the retinal pigmented epithelium (RPE), and neural progenitor (NP) cells. BHK cells are stable, transparent, or non-pigmented, and inexpensive cells that are routinely maintained and easy for screening and visualizing nanomaterial uptake. RPE cells are highly pigmented from melanin and phagocytotic, therefore, a great number of nanoparticles are expected to be taken up in this cell type. NP cells are of interest because these cells are transformed into glial and neuronal cell types. Furthermore, both RPE and NP cells are used in clinical trials as cell replacement strategies to repair vision loss. These cell lines are important for our study to demonstrate the potential of AuNRs for stem cell labeling and tracking using OCT imaging. ${ }^{127-131}$

The two subtypes of AuNRs applied to BHK, RPE, and NP cell lines. The BHK and RPE cells were grown and incubated in DMEM media with $10 \%$ fetal bovine serum and $1 \%$ penicillin/streptomycin at $37^{\circ} \mathrm{C}$ in $5 \% \mathrm{CO}_{2}$ in 24 -well plates in triplicate, while the NP cell lines were cultured in STEMdiff ${ }^{\mathrm{TM}}$ medium. Cellular uptake was visualized by using confocal laser scanning microscopy using fluorescently-labeled AuNRs. Briefly, AuNR-SOA-PC:PE-LRSH-HT (PC:PE-LRSH ratio 9:1) were incubated with 150,000 RPE cells (Figure 2) for $24 \mathrm{~h}$ in DMEM media. Confocal microscopy images at 40x magnification show that with increasing the concentrations of AuNR-SOA-PC:PE-LRSH-HT, $1.6 \times 10^{9}$ to $3.3 \times 10^{10}$ AuNRs $/ \mathrm{mL}$, there is an increase in red fluorescence of the AuNR-SOA-PC:PE-LRSH-HT indicating higher AuNR uptake as more nanoparticles enter the cell (Figure 2). No fluorescence is observed in control samples without AuNR (Figure 2A) and at lower applied AuNR concentrations at $1.6 \times 10^{9}$ nanoparticles/mL (Figure 2B). The blue fluorescence observed is from the DAPI dye used to stain the nucleus of the cell. Similarly, when AuNR-SOA-PC:PE-LRSH-HT were incubated with BHK cells for $24 \mathrm{~h}$, at applied concentrations ranging from $3.3 \times 10^{8}$ to $3.3 \times 10^{10}$ nanoparticles $/ \mathrm{mL}$, a proportional increase in the fluorescence is observed with an increase in AuNRs concentrations (Figure S2) and no fluorescence is observed when AuNRs are absent or are present in low 
concentrations. The observed fluorescence in BHK and RPE cells is not due to free PE-LRSH because before cell studies the hybrid lipid-coated AuNRs are extensively washed until no free dye is observed in the filtrate. Therefore, the observed fluorescence in the cells is because of AuNR-SOA-PC:PE-LRSH-HT internalization into the cell.

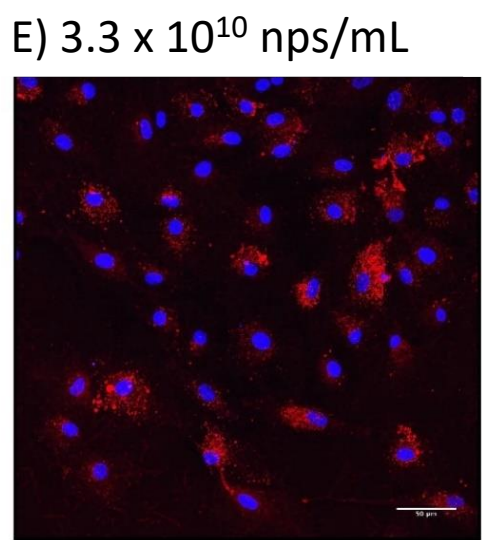

B) $1.6 \times 10^{9} \mathrm{nps} / \mathrm{mL}$

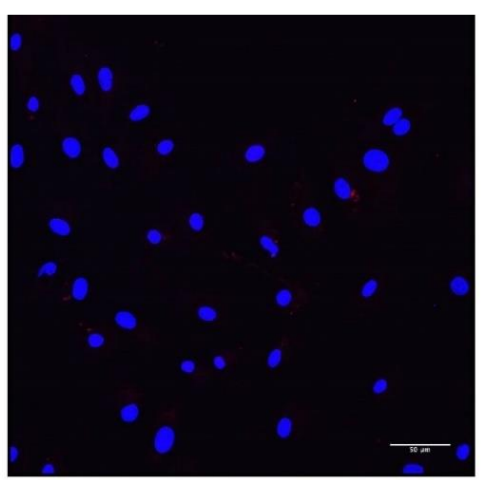

D) $1.6 \times 10^{10} \mathrm{nps} / \mathrm{mL}$

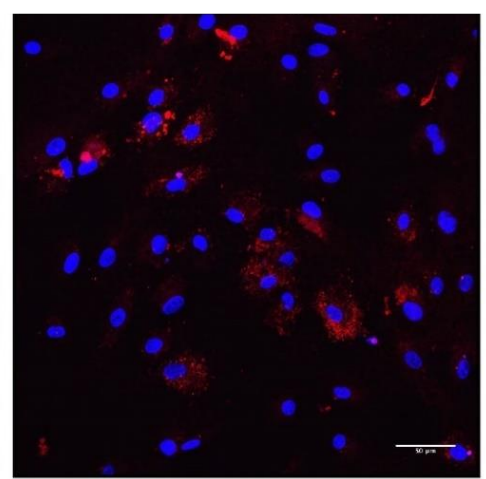

A) No GNR

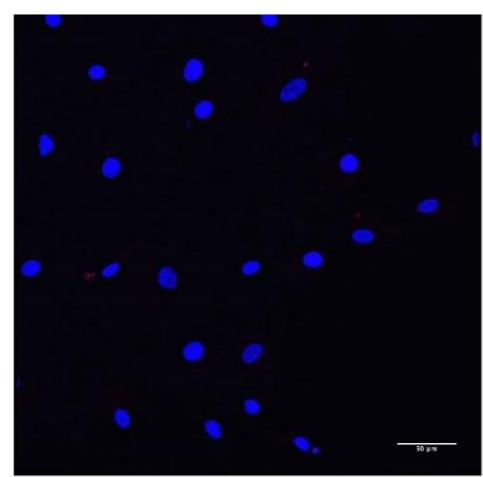

C) $3.3 \times 10^{9} \mathrm{nps} / \mathrm{mL}$

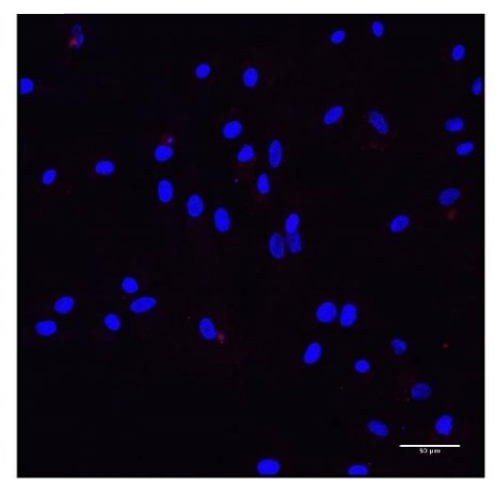

40x images

Figure 2. Confocal laser scanning microscopy images at 40x magnification of RPE cells A) before and B) after the addition of AuNR-SOA-PC:PE-LRSH-HT at an applied concentration of $1.6 \times 10^{9}$ AuNRs/mL, C) $3.3 \times 10^{9}$ nanoparticles AuNRs/mL, D) $1.6 \times 10^{10}$ AuNRs/mL, and E) $3.3 \times 10^{10}$ AuNRs/mL. Blue fluorescence is from the DAPI stained nuclei and red is from the LRSH labelled AuNRs. The scale bars indicate $50 \mu \mathrm{m}$. Cell concentration is 150,000 cells $/ \mathrm{mL}$.

While bright-field imaging is not possible with RPE cells because of their highly pigmented nature, the bright-field images of AuNRs in BHK cells showed that observed red fluorescence overlap where the presence of AuNRs is observed to be physically localized in the cells. Note that 
the fluorescence observed is not due to individual dye molecules or many dye molecules conjugated onto a single AuNR. Instead, the observed fluorescence is due to many dye molecules on a cluster of nanoparticles as the microscopy images are taken at 40x magnification where single nanoparticles cannot be differentiated at microscale resolution. Z-stack analysis of single cells shows that fluorescence is observed throughout the cell confirming that AuNR-SOA-PC:PELRSH-HT are internalized into the cells and not only located on the surface of the cell. Furthermore, magnification at the micron scale of a single cell shows that the AuNR-SOA-PC:PELRSH-HT clusters localized in the cytoplasm of the cell surrounding the nucleus in both BHK and RPE cells (Figure 3). BHK cells in the absence of DAPI nuclear staining show that the AuNRSOA-PC:PE-LRSH-HT are in the cytoplasm surrounding a dark center where the nucleus should be present (Figure 3A). Similarly, in the RPE cells, when the nucleus is stained with DAPI, fluorescence is observed surrounding the nucleus (Figure 3B) with little to no overlap of PELRSH fluorescence overlapping the blue DAPI dye confirming that the AuNRs are mostly localized in the cytoplasm of the cell. Furthermore, the incubation of AuNR-SOA-PC:PE-LRSHHT with RPE and BHK cells show no morphological changes or visible signs of cell death are observed within $24 \mathrm{~h}$ indicating that AuNRs are biocompatible in vitro. Lastly, while the mechanism of uptake was not evaluated in these preliminary studies, it is expected that the AuNRs enter the cell through endocytosis and accumulate in the cytoplasm as visualized by the red fluorescence surrounding the blue DAPI stained nucleus (Figure 3B). These studies demonstrate large (70 x $12 \mathrm{~nm}$ hybrid lipid-coated AuNRs with zwitterionic ionic lipids can enter BHK and RPE cells easily with minimal impact on cell health that is confirmed from cytotoxicity studies, vide infra. 


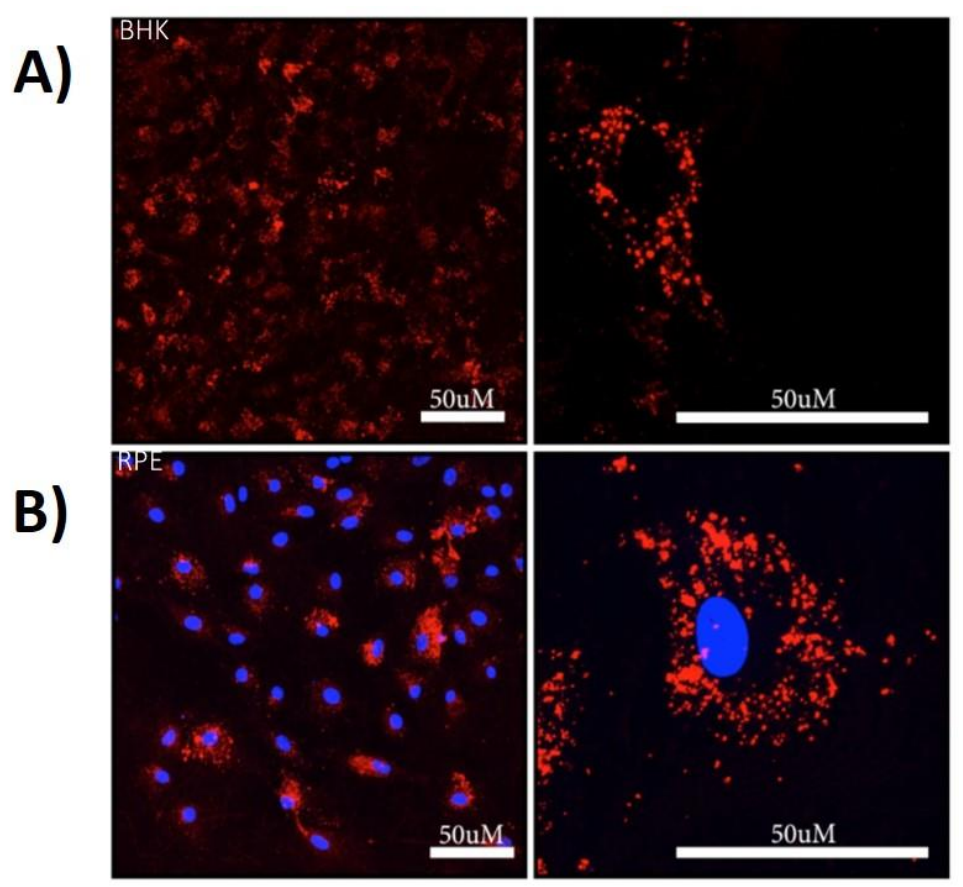

Figure 3. Confocal laser scanning microscopy images (left 40x and right 63x magnification) of A) BHK and B) RPE cells after incubation with an applied concentration of $5 \times 10^{10} \mathrm{AuNRs} / \mathrm{mL}$ of AuNR-SOA-PC:PE-LRSH for $24 \mathrm{~h}$ in DMEM with 150,000 cells/mL. Blue fluorescence is from DAPI stained nuclei and red is from PE-LRSH labeled AuNRs. The scale bars equal $50 \mu \mathrm{m}$ resolution.

\section{The Effect of Surface Charge of Modified AuNRs}

To evaluate the effect of surface charge on the efficiency of uptake AuNRs of the same size and varying charges were studied. AuNRs with hybrid lipid-coated AuNRs were modified with cationic DOTAP or CTAB ligands and the AuNRs with the $\mathrm{mSiO}_{2}$ layer with the proprietary polymer with conjugated LRSH or Cyanine (Cy3) dyes and with varying zeta potentials were purchased (Table 1). Liposomes prepared with PC, PE-LRSH, and DOTAP or CTAB in a 6:1:3 ratio were coated onto AuNRs and anchored with HT to yield AuNR-SOA-PC:PE-LRSHDOTAP-HT and AuNR-SOA-PC:PE-LRSH-CTAB-HT. The AuNR-SOA-PC:PE-LRSHDOTAP-HT were incubated with BHK cells with varying concentrations of AuNRs/mL in DMEM for $24 \mathrm{~h}$. Qualitative inspection of the confocal microscopy images taken at 40x magnification revealed an increase in red fluorescence surrounding the DAPI stained nucleus with increasing 
concentrations of AuNR-SOA-PC:PE-LRSH-DOTAP-HT (Figure 4A). That is when comparing AuNR- SOA-PC:PE-LRSH-DOTAP-HT at $4.1 \times 10^{10}$ AuNRs/mL (Figure 4A) to a similar concentration of AuNR-SOA-PC:PE-LRSH-HT (5 x $10^{10}$ AuNRs $/ \mathrm{mL}$ ) (Figure 3B) without DOTAP, there is a noticeable increase in the red fluorescence AuNR-SOA-PC:PE-LRSHDOTAP-HT around the cell nuclei suggesting more AuNR-SOA-PC:PE-LRSH-DOTAP-HT uptake. A similar increase in fluorescence is observed when AuNRs are prepared with CTAB, another cationic ligand (Figure S3). Confocal and bright-field images of AuNR-SOA-PC:PELRSH-CTAB-HT with a 6:1:3 ratio of PC:PE-LRSH:CTAB show a similar enhancement fluorescence and clustering of AuNRs in the cellular cytoplasm of BHK cells (Figure S4) compared to AuNR-SOA-PC:PE-LRSH-HT (Figure 3A) at similar concentrations $\left(5 \times 10^{10}\right.$ AuNRs $/ \mathrm{mL}$ ). This confirms that when cationic ligands are present there is increased uptake of hybrid lipid-coated AuNR into cells. The increased cellular uptake of lipid-coated hybrid AuNRs containing DOTAP or CTAB suggests different mechanisms are responsible for the cellular uptake and needs to be investigated further. Lastly, visual inspection showed noticeable cell death with AuNR-SOA-PC:PE-LRSH-CTAB-HT compared to AuNR-SOA-PC:PE-LRSH-CTAB-HT. This is not surprising as $\mathrm{CTAB}$ is known to be toxic and is not an ideal ligand for coating nanoparticles. ${ }^{132-134}$ 


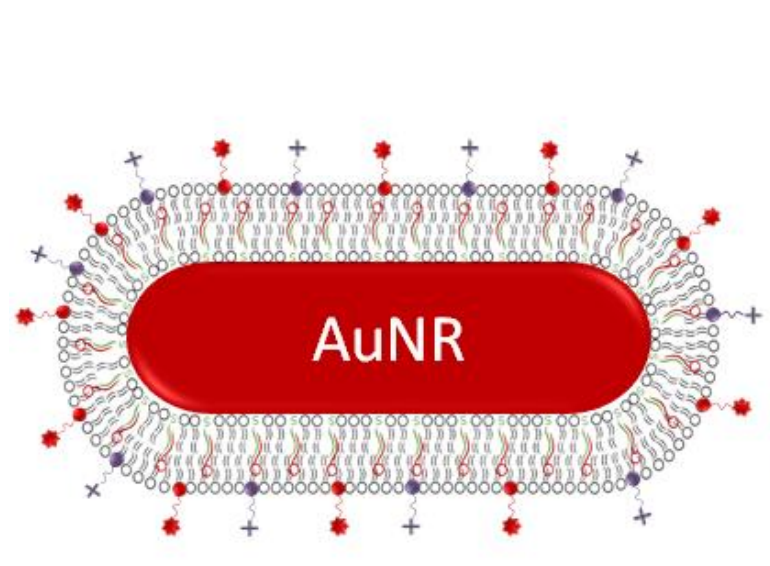

a)
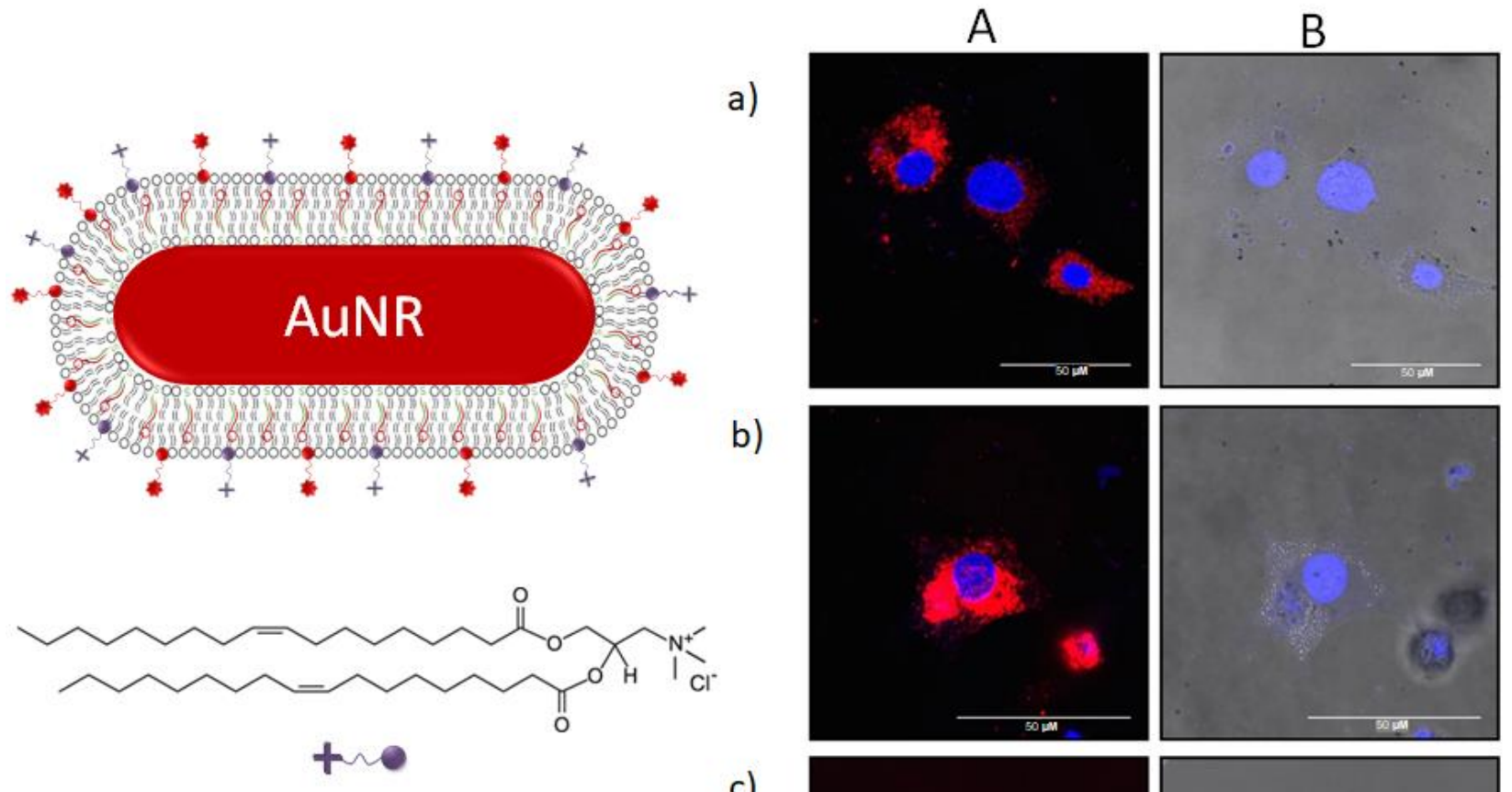

b)
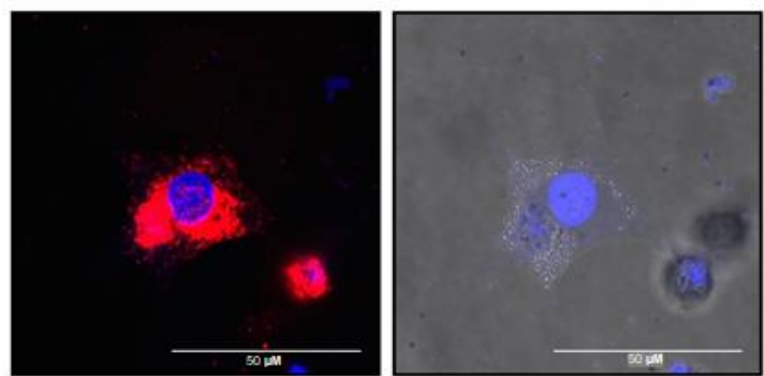

1,2-di-(9Z-octadecenoyl)-3-trimethylammoniumpropane chloride (DOTAP)
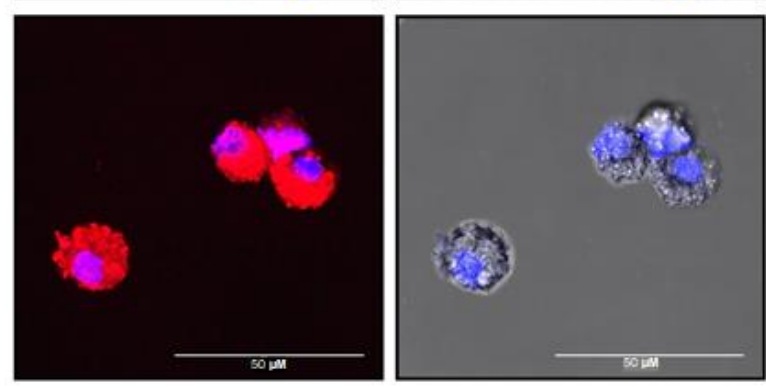

Figure 4. A) Confocal laser scanning microscopy images at 40x magnification with a $4 \mathrm{x}$ digital zoom and B) bright-field images of AuNR-SOA-PC:PE-LRSH-HT incubated at a) $4.1 \times 10^{10}$ $\mathrm{nps} / \mathrm{mL}$ b) $8.3 \times 10^{10} \mathrm{nps} / \mathrm{mL}$ and c) $4.1 \times 10^{11} \mathrm{nps} / \mathrm{mL}$ incubated with $150,000 \mathrm{RPE}$ cells per $\mathrm{mL}$ for $24 \mathrm{~h}$ in DMEM. Blue fluorescence is the DAPI stained nuclei and red are PE-LRSH-labeled AuNRs. The scale bars indicate $50 \mu \mathrm{m}$.

In contrast, incubation of $\mathrm{AuNR}-\mathrm{mSiO}_{2}$-polymer-Cy3 nanoparticles with an average length of $55 \mathrm{~nm}$ and width of $10 \mathrm{~nm}$ with a zeta potential of $+5 \mathrm{mV}$ and an applied concentration of $8 \mathrm{x}$ $10^{10}$ AuNRs/mL with BHK cells in DMEM for $24 \mathrm{~h}$ showed an increase in red fluorescence surrounding the DAPI stained nucleus from the Cy3-conjugated onto the polymer on the AuNR surface (Figure 5A). This suggests that AuNRs-mSiO 2 -polymer-Cy3 are also being taken up into the cytoplasm of the cells. With increasing applied concentrations of $\mathrm{AuNR}-\mathrm{mSiO}_{2}$-polymer-Cy3 from $8 \times 10^{10} \mathrm{AuNRs} / \mathrm{mL}$ to $4 \times 10^{12} \mathrm{AuNRs} / \mathrm{mL}$ there is the increasing appearance of red 
fluorescence that eventually overlaps with the DAPI stained nucleus (Figure 5A, b-e). This overlap in fluorescence suggests that the AuNRs-mSiO 2 -polymer-Cy3 are localized in the cytoplasm as well as the exterior cell surface as supported in the bright field images where an abundance of AuNRs-mSiO 2 -polymer-Cy3 nanoparticles completely cover the cell body (Figure 5B, e). In both BHK and RPE cells, there is an accumulation of AuNRs inside and outside of the cells and the AuNRs appear aggregated (Figure S5). The aggregation of nanomaterials is known to play a significant role in hindering the cellular uptake of nanomaterials. ${ }^{135-137}$ While the confocal and bright-field images appear to show greater uptake of AuNR-mSiO 2 -polymer-Cy3 nanoparticles with a zeta potential of $+5 \mathrm{mV}$ compared to hybrid lipid-coated AuNRs with an overall slightly negative zeta potential, in general, it at higher concentrations $4 \times 10^{12} \mathrm{AuNRs} / \mathrm{mL}$ there is a loss of cell adhesion to the culture dish and globular GNR aggregation.

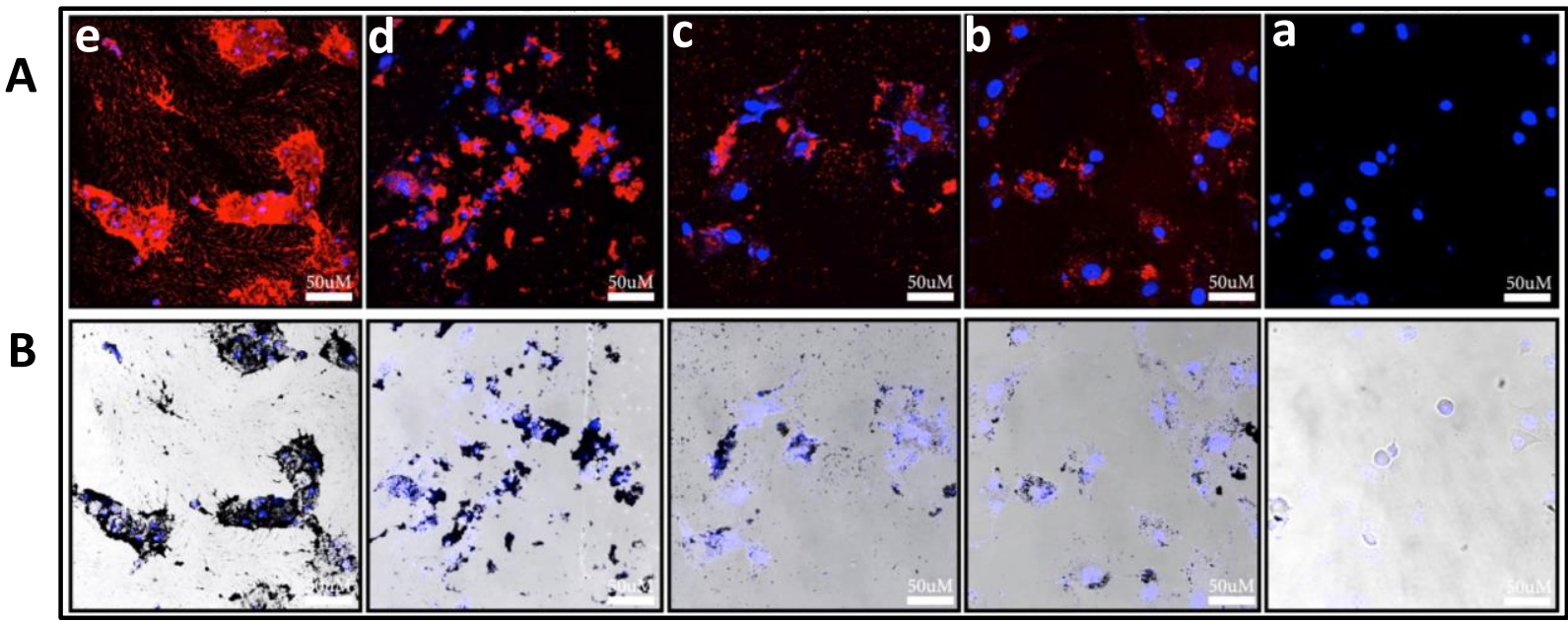

Figure 5: Representative A) confocal laser scanning microscopy images and B) bright-field images at 40x magnification of BHK cells a) without AuNRs and BHK cells incubated with increasing concentrations of AuNR-mSiO 2 -polymer-Cy3 at b) $8.0 \times 10^{10} \mathrm{nps} / \mathrm{mL}$ b) $4.0 \times 10^{11}$ $\mathrm{nps} / \mathrm{mL}$, c) $8.0 \times 10^{11} \mathrm{nps} / \mathrm{mL}$ and d) $4.0 \times 10^{12} \mathrm{nps} / \mathrm{mL}$. All AuNR samples were incubated with 150,000 cells/mL for $24 \mathrm{~h}$ in DMEM. Blue fluorescence is the DAPI stained nuclei and red are Cy3-labeled polymer-coated $\mathrm{mSiO}_{2}$ layered AuNRs. The scale bars indicate $50 \mu \mathrm{m}$. 
To further investigate the impact of increasing the cationic charge of the $\mathrm{mSiO}_{2}$ polymercoated AuNRs, a series of AuNRs- $\mathrm{mSiO}_{2}$-polymer-LRSH nanoparticles with an average length of $95 \mathrm{~nm}$ and width of $25 \mathrm{~nm}$ with increasing positive zeta potential (Table 1) were incubated with BHK cells (Figure 6). The applied AuNRs-mSiO 2 -polymer-LRSH concentration $\left(5 \times 10^{10}\right.$ AuNRs $/ \mathrm{mL}$ ) are the same in each sample with 150,000 cells $/ \mathrm{mL}$. It should be noted that this subtype of AuNRs is "sticky" and adheres to the surfaces such as pipette tips when working with them. Representative confocal and microscopy images show that all AuNRs are taken up into the BHK cells and to varying degrees based on the amount of fluorescence observed (Figure 6). Surprisingly, while the bright field images (Figure 6B) show lots of nanoparticle aggregates an increase in fluorescence is not observed with an increasing cationic charge of the AuNRs (Figure 6A). Variable fluorescence is observed when AuNRs-mSiO 2 -polymer-LRSH with zeta potentials of $+8,+30,+35 \mathrm{mV}$, and +50 . Minimal or no fluorescence is observed with AuNRs-mSiO $2_{2}-$ polymer-LRSH with +8 and $+50 \mathrm{mV}$ (Figure 6A). Closer inspection of images shows punctate fluorescence staining from AuNRs-mSiO ${ }_{2}$-polymer-Cy3 at $+5 \mathrm{mV}$ and $\mathrm{AuNRs}-\mathrm{mSiO}_{2}$-polymerLRSH at $+30 \mathrm{mV}$ zeta potential (Figure 6B) indicating some internalization of the AuNRs in the cytoplasm of the cells surrounding the DAPI stained nucleus. In contrast, globular fluorescence is observed with AuNRs-mSiO 2 -polymer-LRSH with a $+30 \mathrm{mV}$ zeta potential (Figure 6A) suggesting a lack of internalization as confirmed in the bright field images where the AuNRs appear to be agglomerated on the surface (Figure 6B). Based on these observations the cationic AuNRs-mSiO 2 -polymer-LRSH nanoparticles have a greater propensity for nanoparticlenanoparticle interactions and the agglomerates observed are most likely due to the interaction of the AuNRs-mSiO 2 -polymer-LRSH with proteins in the media that affects nanoparticle stability and cellular uptake. 

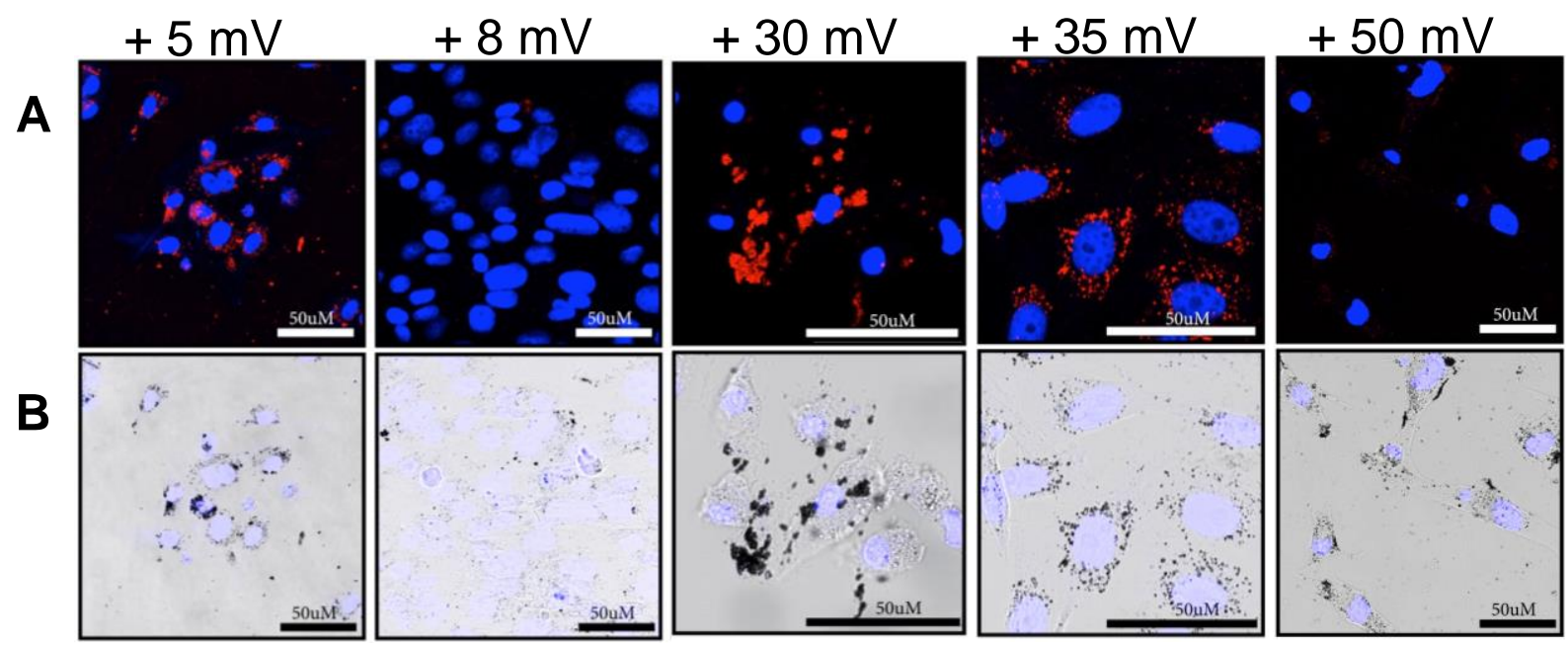

Figure 6: Representative A) confocal laser scanning microscopy images and B) bright-field images at 40x magnification with a $4 \mathrm{x}$ digital zoom of BHK cells incubated with $5.0 \times 10^{10}$ AuNRs/mL of AuNR-mSiO 2 -polymer-LRSH with increasing positive charge (right to left). All AuNR-mSiO 2 -polymer-LRSH samples were incubated with 150,000 cells $/ \mathrm{mL}$ for $24 \mathrm{~h}$ in DMEM. Blue fluorescence is the DAPI stained nuclei and red are LRSH-labeled polymer-coated $\mathrm{mSiO}_{2}$ layered AuNRs. The scale bars indicate $50 \mu \mathrm{m}$.

Interestingly, in a qualitative comparison, with the number of AuNRs-mSiO 2 -polymerLRSH nanoparticles visibly present in the BHK cells (Figure 7B and 8B), it is interesting to note that the fluorescence is not as bright compared to the hybrid lipid-coated AuNRs of a similar concentration and magnification (Figure 2 and 3). In some cases, there is minimal, or no fluorescence observed particularly with AuNRs-mSiO 2 -polymer-LRSH that highly positive zeta potential (Figure 6A). A major difference between the AuNRs-mSiO 2 -polymer-LRSH and the hybrid lipid-coated AuNRs is the surface charge and ligand coating on the AuNR surface. The AuNRs-mSiO 2 -polymer-LRSH is coated with a proprietary positively charged polymer coating that is very "sticky" such that it interacts with the pipette tips and cell culture plates compared to the hybrid lipid-coated AuNRs. Their inherent "sticky" nature is the driving force between nanoparticle-nanoparticle, nanoparticle-protein, nanoparticle-cell interactions. The level of nanoparticle-nanoparticles and nanoparticle-cell interactions is seen in Figure 7 where the AuNRs 
are internalized into the cytoplasm as aggregates surrounding the nucleus and are on the surface of the cell. The result nanoparticle-nanoparticle interactions observed here are hypothesized to induce a fluorescence quenching effect and are consistent with that observed with aggregation of polymeric and metal-based nanomaterials. ${ }^{138-141}$ The level of nanoparticle aggregation observed with the AuNRs-mSiO 2 -polymer-LRSH on the surface of cells would not be a concern for applications where the goal is to visualize the delivery therapeutics and cell death, it could be problematic if AuNR-labeled cells were to be used in cell transplantation studies. Since these surface-bound AuNRs could dissociate from the surface and migrate to non-transplanted cells in the eye leading to false positives using bioimaging methods designed to track transplanted cells.

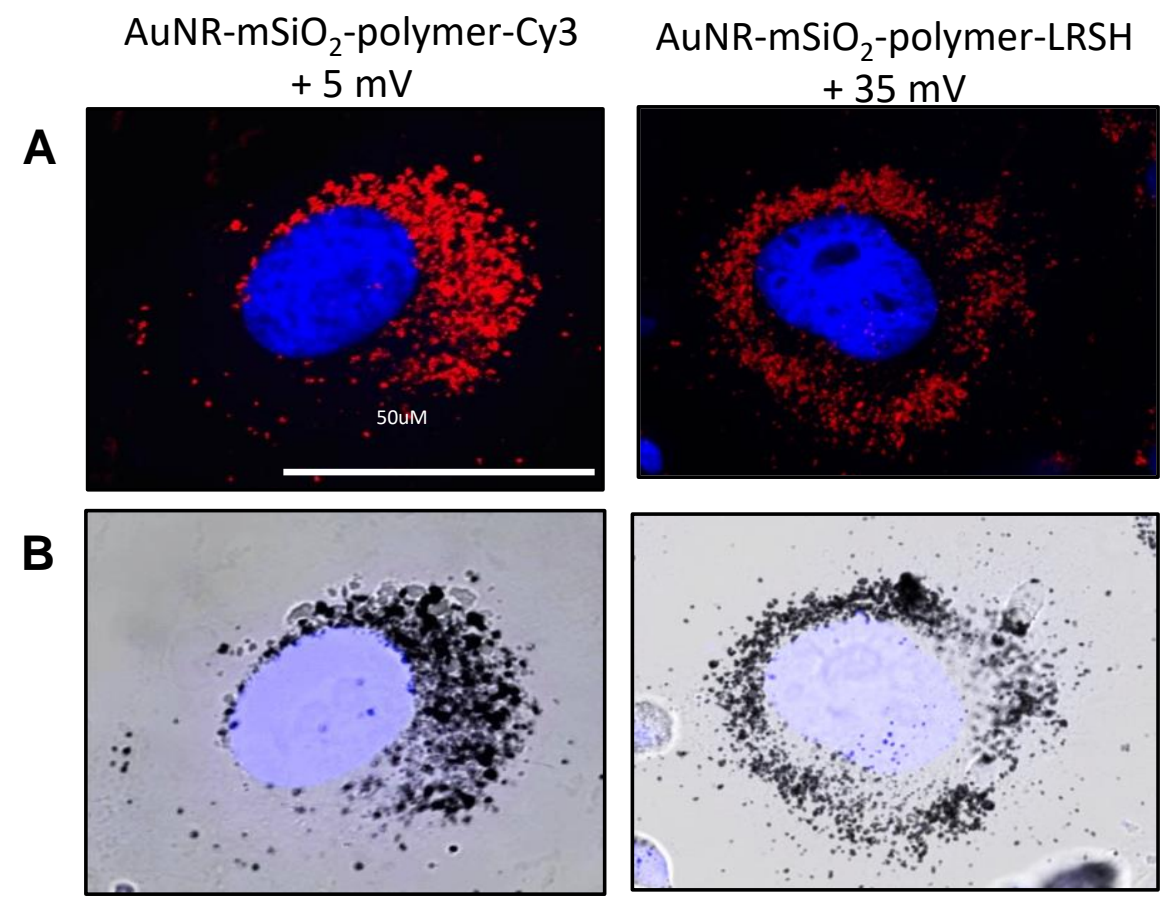

Figure 7: Representative A) confocal fluorescence microscopy and B) bright-field images at 63x magnification of BHK cells incubated with $5.0 \times 10^{10} \mathrm{AuNRs} / \mathrm{mL}$ of AuNR-mSiO 2 -polymer-Cy3 $(55 \times 10 \mathrm{~nm})$ with $+5 \mathrm{mV}$ zeta potential and AuNR-mSiO 2 -polymer-LRSH $(96 \times 25 \mathrm{~nm})$ with a $+35 \mathrm{mV}$ zeta potential. All $\mathrm{mSiO}_{2}$-polymer-AuNR samples were incubated with $150,000 \mathrm{cells} / \mathrm{mL}$ for $24 \mathrm{~h}$ in DMEM. Blue fluorescence is the DAPI stained nuclei and red are Cy3 or LRSH dyelabeled polymer-coated $\mathrm{mSiO}_{2}$ layered AuNRs. The scale bars indicate $50 \mu \mathrm{m}$. 


\section{The effect of Cell-penetrating peptides on cellular uptake}

In addition to modifying the surface of the AuNRs cationic charge, the AuNRs were also modified with the cell-penetrating peptides RGD, as another strategy for enhancing the cellular uptake and biocompatibility of the AuNRs. Hybrid lipid-coated AuNRs were prepared RGD peptides with and without DOTAP, AuNR-SOA-PC:PE-RGD:PE-LRSH (lipid ratio of 8:1:1), and with AuNR-SOA-PC:PE-RGD:PE-LRSH:DOTAP (lipid ratio of 7:1:1:1). The combination of the RGD peptide and DOTAP was employed to examine if the addition of the RGD and cationic agent further enhances cellular uptake than the cationic ligand or cell-penetrating peptide independently. A comparison of representative confocal microscopy images of AuNR-SOA-PC:PE-RGD:PELRSH:HT and AuNR-SOA-PC:PE-RGD:PE-LRSH:DOTAP-HT shows a similar amount of red fluorescence in NP cells (Figure 8, B and C) suggesting that a similar amount of AuNRs are taken up into the NP cell. Furthermore, when AuNR-SOA-PC:PE-RGD:PE-LRSH:HT and AuNR-SOAPC:PE-RGD:PE-LRSH:DOTAP-HT ( 5 x $10^{10}$ AuNRs/mL) are compared to AuNR-SOA-PC:PELRSH:DOTAP-HT (4.1 x 10 10 AuNRs/mL), which has a 6:1:3 ratio of PC:PE-LRSH:DOTAP, a similar amount of red fluorescence is observed (Figure 8A). Similar levels of cellular internalization are observed AuNR-SOA-PC:PE-RGD:PE-LRSH:HT and AuNR-SOA-PC:PERGD:PE-LRSH:DOTAP-HT in BHK cells (Figure S4). The zeta potential of all these hybrid lipid-coated AuNRs is similar (-7.8 to -4.4 mV). Therefore, similar uptake of these types of AuNRs is expected, and an increase in RGD peptide content of cationic ligands in the liposome formulation is expected to enhance the internalization of the AuNRs. Despite the variance in coating and except for the AuNR platform with CTAB, the addition of RGD or DOTAP in varying composition into the liposome formulation did have any significant visually observable adverse effects on BHK, RPE, and NP cell health with hybrid lipid-coated AuNRs and suggests that these nanoparticles are biocompatible. Furthermore, these observations are consistent with that previous studies where 
similar hybrid lipid-coated spherical AuNPs (10-20 nm) and triangular plate-shaped AgNPs (32 $\mathrm{nm}$ ) of various size and shapes with a similar hybrid lipid-coating are found to be non-toxic and biocompatible in vivo using embryonic zebrafish model. ${ }^{106,110,112}$

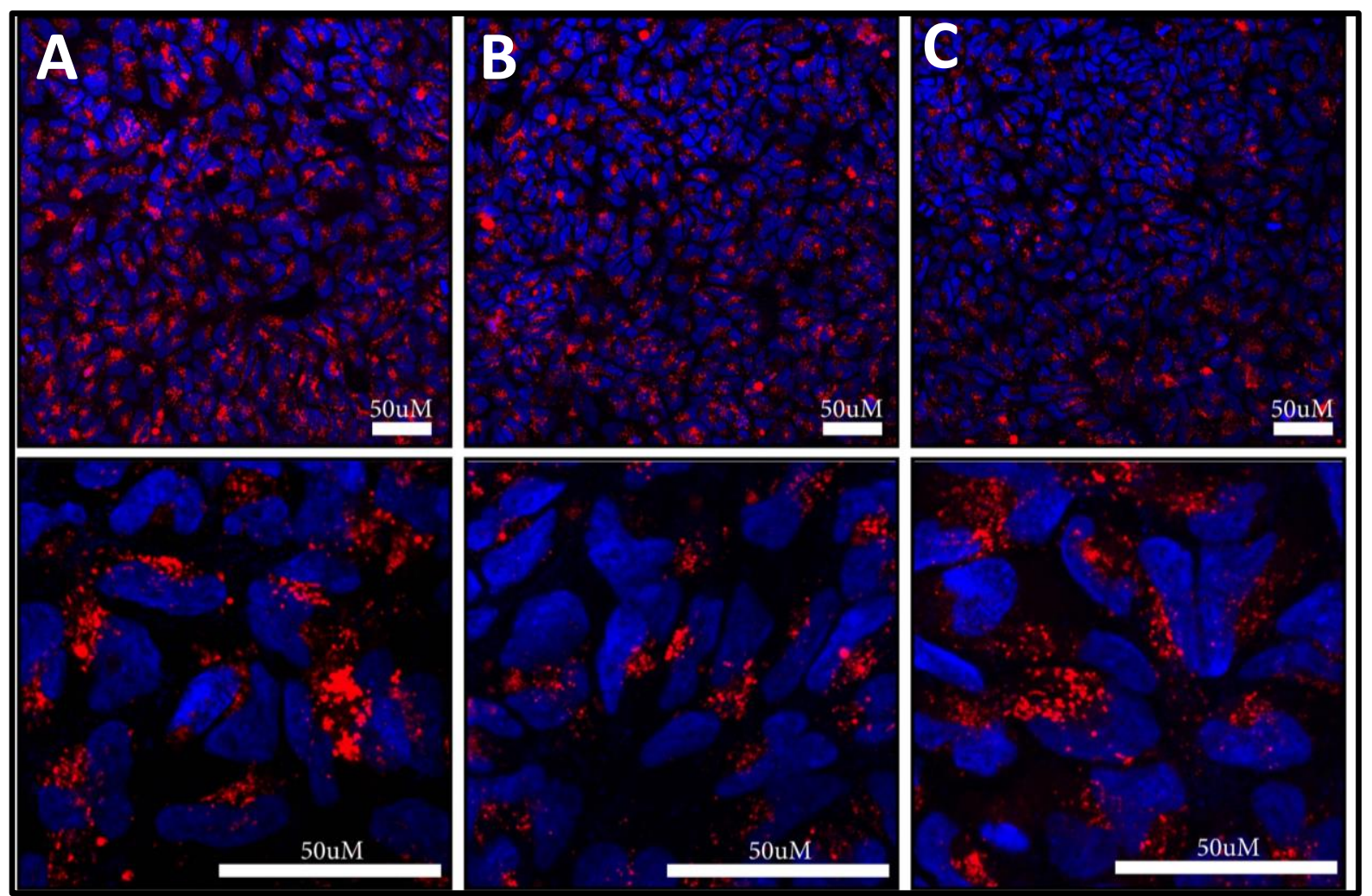

Figure 8. Confocal laser scanning microscopy images of NP cells incubated with $5 \times 10^{10}$ AuNRs/mL of A) AuNR-SOA-PC:PE-LRSH:DOTAP-HT B) AuNR-SOA-PC:PE-LRSH:PERGD-HT and C) AuNR-SOA-PC:PE-LRSH:PE-RGD-DOTAP-HT in DMEM for $24 \mathrm{~h}$. Blue fluorescence is the DAPI stained nuclei and red are PE-LRSH-labeled AuNRs. The top panel is at 40x magnification, and the bottom panel is at 40x magnification with a 4x digital zoom. The scale bars indicate $50 \mu \mathrm{m}$.

\section{Quantitative Cellular Uptake Studies (ICP-MS) and TEM}

To confirm that the AuNR platforms are taken into the cytoplasm and not just adhering to the surface of the cell, inductively coupled plasma mass spectrometry (ICP-MS) was used to quantify the number of AuNRs taken up per cell for both subtypes. Approximately $5 \times 10^{10}$ AuNRs/mL of AuNR-SOA-PC:PE-LRSH:DOTAP, AuNR-SOA-PC:PE-RGD:PE-LRSH, or 
AuNRs-mSiO 2 -polymer-LRSH with a $+35 \mathrm{mV}$ zeta potential were applied and incubated with 1 x $10^{6} \mathrm{BHK}$ cells $/ \mathrm{mL}$ in DMEM media at $37^{\circ} \mathrm{C}$ for $24 \mathrm{~h}$. The cells were harvested by centrifugation and washed with copious amounts of $10 \mathrm{mM}$ PBS buffer $\mathrm{pH} 7.4$ to remove surface-bound AuNRs. The cells were digested using standard protocols for ICP-MS analysis to detect the Au content left in the washed samples. The Au content and the dimensions of the AuNRs were used to estimate the number of AuNRs internalized per cell (Supporting Information). After $24 \mathrm{~h}$ approximately 5400 AuNRs- $\mathrm{mSiO}_{2}$-polymer-LRSH with a $+35 \mathrm{mV}$ zeta potential were detected in the $\mathrm{BHK}$ cells. In contrast, about 3067 and 3126 of AuNR-SOA-PC:PE-RGD:PE-LRSH and AuNR-SOAPC:PE-LRSH:DOTAP-HT, were found to be internalized into the BHK cells. The similar amount of cellular uptake of the hybrid lipid-coated AuNRs is consistent with comparable levels of fluorescence observed in the confocal fluorescence microscopy images (Figure 6 A and B). While the ICP-MS analysis shows the AuNRs-mSiO 2 -polymer-LRSH with a $+35 \mathrm{mV}$ zeta potential had 2300 more AuNRs more than the hybrid lipid-coated AuNRs, the fluorescence is not as bright because of the self-quenching from aggregation. Similar differences in uptake are observed with AuNRs-mSiO 2 -polymer-LRSH with a $+50 \mathrm{mV}$ zeta potential, AuNR-SOA-PC:PE-RGD:PELRSH, and AuNR-SOA-PC:PE-LRSH:DOTAP-HT in phagocytotic RPE cells (Figure S6). Interestingly, AuNRs-mSiO 2 -polymer-LRSH with a $+50 \mathrm{mV}$ nanoparticles show minimal or no fluorescence even with less aggregation (Figure 6A), and higher nanoparticle cellular uptake (Figure S6) than the hybrid lipid-coated AuNRs. The amount aggregation and uptake observed for the AuNRs-mSiO${ }_{2}$-polymer-LRSH nanoparticles are consistent with visual cellular assessment by bright field-microscopy in both cell lines. Since cell membranes are predominantly negatively charged, the probability of cationic AuNRs interacting with the surface of the negatively charged cells and proteins in the media is greater. It is also possible that because of the "stickiness" of the AuNRs-mSiO 2 -polymer-LRSH nanoparticles that not all the surface-bound AuNRs were removed 
by washing and could also explain the higher intracellular uptake observed for the $\mathrm{AuNRs}-\mathrm{mSiO}_{2}$ polymer-LRSH nanoparticles (Figure 9).

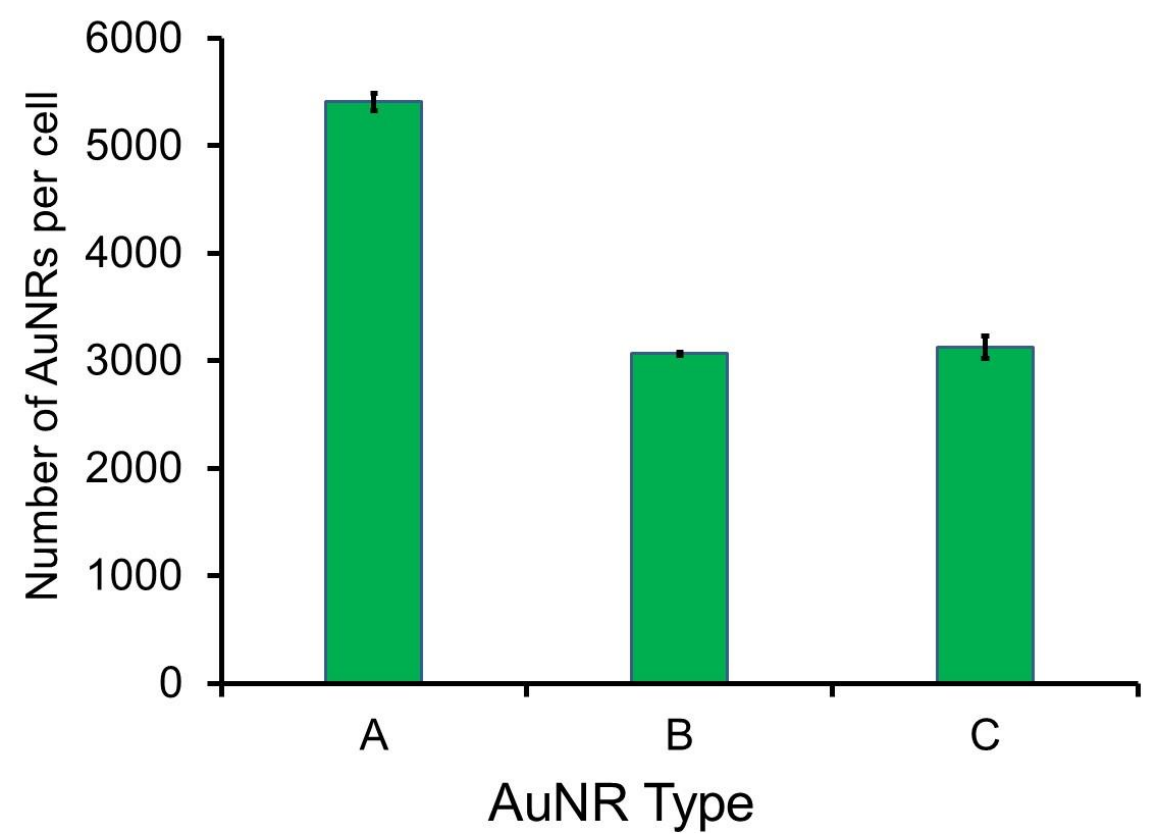

Figure 9: Quantification of AuNR uptake in BHK cells by ICP-MS. 5x10 AuNRs/mL of A) AuNRs-mSiO 2 -polymer-LRSH at $+35 \mathrm{mV}$, B) AuNR-SOA-PC:PE-LRSH:DOTAP, C) AuNRSOA-PC:PE-RGD:PE-LRSH was incubated with $10^{6} \mathrm{BHK}$ cells $/ \mathrm{mL}$ for $24 \mathrm{~h}$ in DMEM at $37^{\circ} \mathrm{C}$. Data reported as average number of AuNRs/cell from triplicate trials.

Transmission electron microscopy (TEM) was also used to visually confirm the intracellular localization of the AuNRs. The AuNR-SOA-PC:PE-RGD:PE-LRSH was incubated with BHK cells for $24 \mathrm{~h}$ followed by TEM imaging with and without an objective aperture (Figure 10). The TEM images black granules inside of the BHK cell cytosol, further confirming that the lipid-coated AuNR hybrids are taken up into the cells. The 69 x 12 nm AuNRs can be seen localized into lysosomal compartments in small clusters or as single nanoparticles (Figure 10A). Not surprisingly, the AuNRs-mSiO 2 -polymer-LRSH nanoparticles with $+50 \mathrm{mV}$ appeared glomerated inside of the cell and are consistent with the confocal and bright field microscopy imaging. 

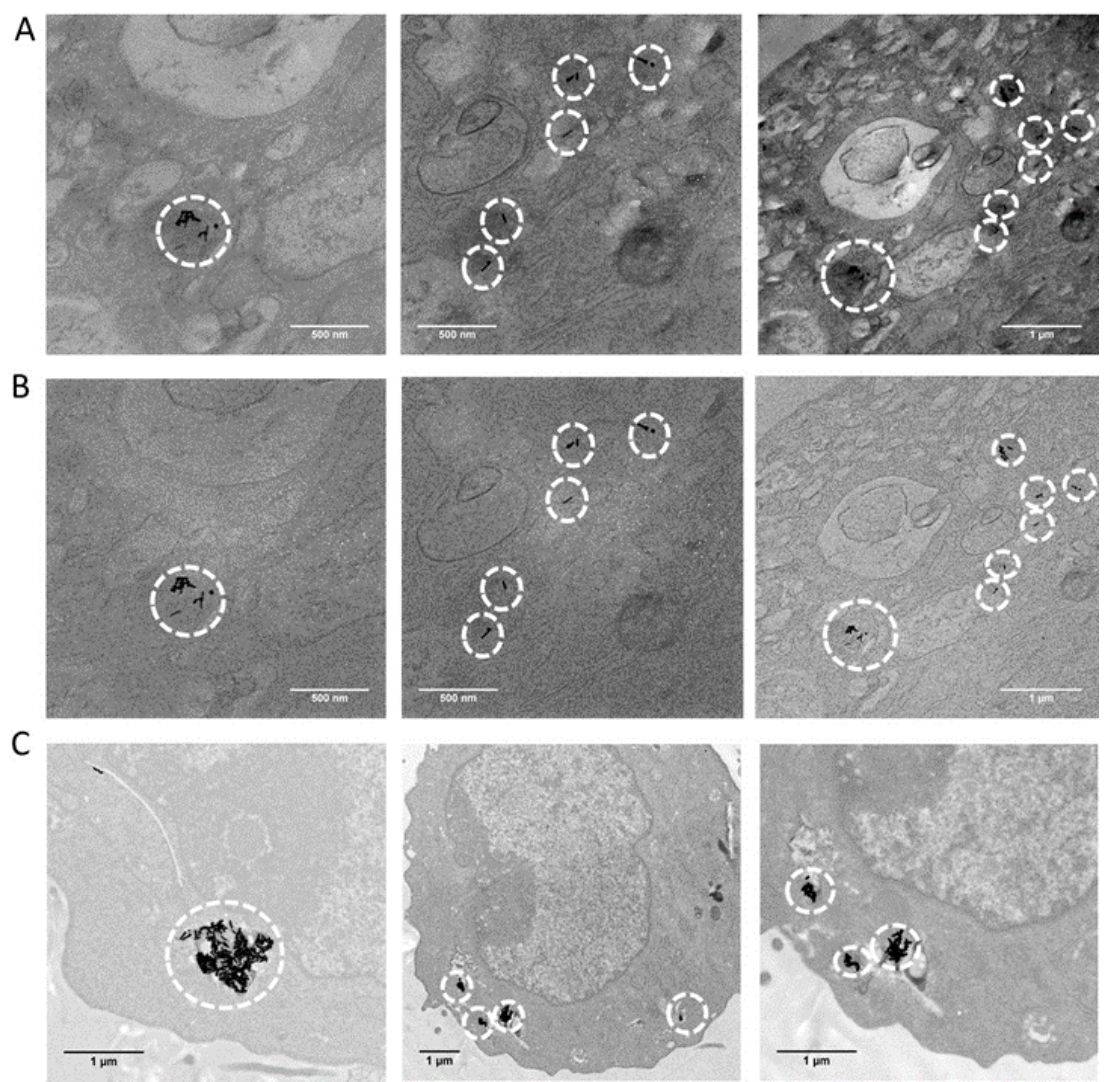

Figure 10: Transmission electron microscopy imaging of BHK cells after $24 \mathrm{~h}$ incubated with AuNR-PC:PE-RGD:PE-LRSH (8:1:1) (\#9 Table 1) stained with 1\% Osmium tetroxide (A) with objective aperture and (B) without objective aperture. TEM images reveal accumulation of AuNRs as black granules in cytosol (red arrows), and C) AuNRs- $\mathrm{mSiO}_{2}$-polymer-LRSH nanoparticles \#5 unstained. The scale bars indicate $500 \mathrm{~nm}$ (2 left columns) and $1 \mu \mathrm{M}$ (far right column and bottom).

\section{Evaluating the effect of cell culture medium on nanoparticle stability}

The stability of nanomaterials is influenced by chemical and physical transformations upon contact with biological environments such as saliva, blood, and media. For example, when nanoparticles are exposed to the bloodstream they interact with opsonin proteins that attach to the surface of the nanoparticles forming a protein corona. ${ }^{101-104,52,57-59}$ Protein-nanoparticle interaction then triggers the mononuclear phagocytic system that recognizes the protein-nanoparticle complexes for clearance and accumulates in the liver and spleen. Concomitantly, this results in low targeting efficiency, poor delivery of drug and imaging agents, and toxicity. The surface 
chemistry of the nanoparticles can also trigger aggregation resulting in nanoparticle-nanoparticle interactions from components of the media such as proteins. ${ }^{78,} 142-144$ While aggregated nanoparticles in the cell can lead to longer intracellular retention of AuNRs and is a desirable property for cell-labeling and imaging, ${ }^{145}$ in most cases nanoparticle aggregation in the media is not desired. Large aggregates formed outside of the cell are not expected to be taken up easily as seen with transferrin-coated AuNPs ${ }^{135-136}$ and can significantly affect uptake efficiency and cytotoxicity. Stability studies in cell culture media are important to examine the effect of the nanoparticle coating on nanoparticle stability resulting in aggregation from nanoparticlenanoparticle interactions and nanoparticle-cell interactions, which affect cellular uptake efficiency and cytotoxicity. ${ }^{146}$ Therefore, to understand the impact of the media on the stability of the AuNRs, hybrid lipid-coated AuNRs and AuNRs-mSiO 2 -polymer-LRSH were incubated in water, $10 \mathrm{mM}$ PBS buffer $\mathrm{pH}$ 7.4, NP media, and DMEM (Figure 11). AuNRs-mSiO 2 -polymer-LRSH nanoparticles with zeta potentials at $+50 \mathrm{mV}$ and $+35 \mathrm{mV}$ show various levels of aggregation in all four media used in the study (Figure 11 A and B). AuNRs-mSiO ${ }_{2}$-polymer-LRSH nanoparticles with a $+50 \mathrm{mV}$ zeta potential show significant aggregation NP media followed by 10 mM PBS buffer pH 7.4 (Figure 11A), while AuNRs-mSiO2-polymer-LRSH nanoparticles with $\mathrm{a}+35 \mathrm{mV}$ zeta potential show a significant amount of aggregation in water $>\mathrm{NP}$ media $>$ DEMEM $>10 \mathrm{mM}$ PBS buffer (Figure 11B). Interestingly, the AuNRs-mSiO 2 -polymer-LRSH nanoparticles with a $+35 \mathrm{mV}$ zeta potential is less aggregated in $10 \mathrm{mM} \mathrm{PBS} \mathrm{pH} 7.4<$ DMEM $<$ NP media suggesting the $\mathrm{pH}$ and the components play a role in the stabilization of the AuNRs by minimizing nanoparticle-nanoparticle interactions. The hybrid lipid-coated AuNRs, the AuNRSOA-PC:PE-RGD:PE-LRSH:HT with a $\quad-4.8 \mathrm{mV}$ and AuNR-SOA-PC:PE-RGD:PELRSH:DOTAP-HT with $-6.6 \mathrm{mV}$ zeta potentials were mostly stable in all media except NP media (Figure 11C and D). The AuNR-SOA-PC:PE-RGD:PE-LRSH:DOTAP-HT shows significant 
aggregation in NP media and slight aggregation in $10 \mathrm{mM}$ PBS buffer $\mathrm{pH} 7.4$ (Figure 11D) while AuNR-SOA-PC:PE-RGD:PE-LRSH:HT with the more negative zeta potential showed significant aggregation in NP media (Figure 11C). All subtypes of AuNRs show significant aggregation in NP media, which suggests that specific protein(s) or small molecules in this media type interacts with the AuNR surface to drive nanoparticle-nanoparticle interactions. The AuNR-SOA-PC:PERGD:PE-LRSH:DOTAP-HT has a slightly more negative charge than AuNR-SOA-PC:PERGD:PE-LRSH:HT nanoparticles allowing for more nanoparticle interactions with small molecules or proteins in the media. Similarly, the AuNRs-mSiO 2 -polymer-LRSH nanoparticles with a $+50 \mathrm{mV}$ zeta potential (Figure 11A) show more aggregation in the NP media than the subtype with a +35 zeta potential (Figure 11B). The aggregation observed in the media explains why so many AuNRs-mSiO 2 -polymer-LRSH are surrounding the cell. Both BHK and RPE cells in DMEM were used for the quantification of cellular uptake by ICP-MS, where less aggregation was observed for AuNRs-mSiO ${ }_{2}$-polymer-LRSH, AuNR-SOA-PC:PE-LRSH:DOTAP, and AuNR-SOA-PC:PE-RGD:PE-LRSH. Although less aggregation is observed for the hybrid lipidcoated AuNRs compared to AuNRs-mSiO 2 -polymer-LRSH, higher uptake is observed with the positively charged nanoparticles according to the ICP-MS studies. Although the hybrid lipidcoated AuNRs have a slight overall negative charge that would hinder uptake into negatively charged cells about 3000 AuNRs are taken up in each cell. These observations suggest that a unique protein corona is formed around positively and negatively charged AuNRs to produce surface chemistry with different functional groups that allow for different cellular uptake efficiencies via receptor-mediated endocytosis. ${ }^{147-152}$ In studies with serum proteins, over 70 different proteins can be adsorbed with different grafting densities on the nanoparticle surfaces. ${ }^{142}$ It is likely that the same type and number of proteins in the DMEM are presented on the AuNRs- 
mSiO 2 -polymer-LRSH, AuNR-SOA-PC:PE-LRSH:DOTAP, and AuNR-SOA-PC:PE-RGD:PE-

LRSH nanoparticles that result in similar uptake in BHK and RPE cells observed by ICP-MS.

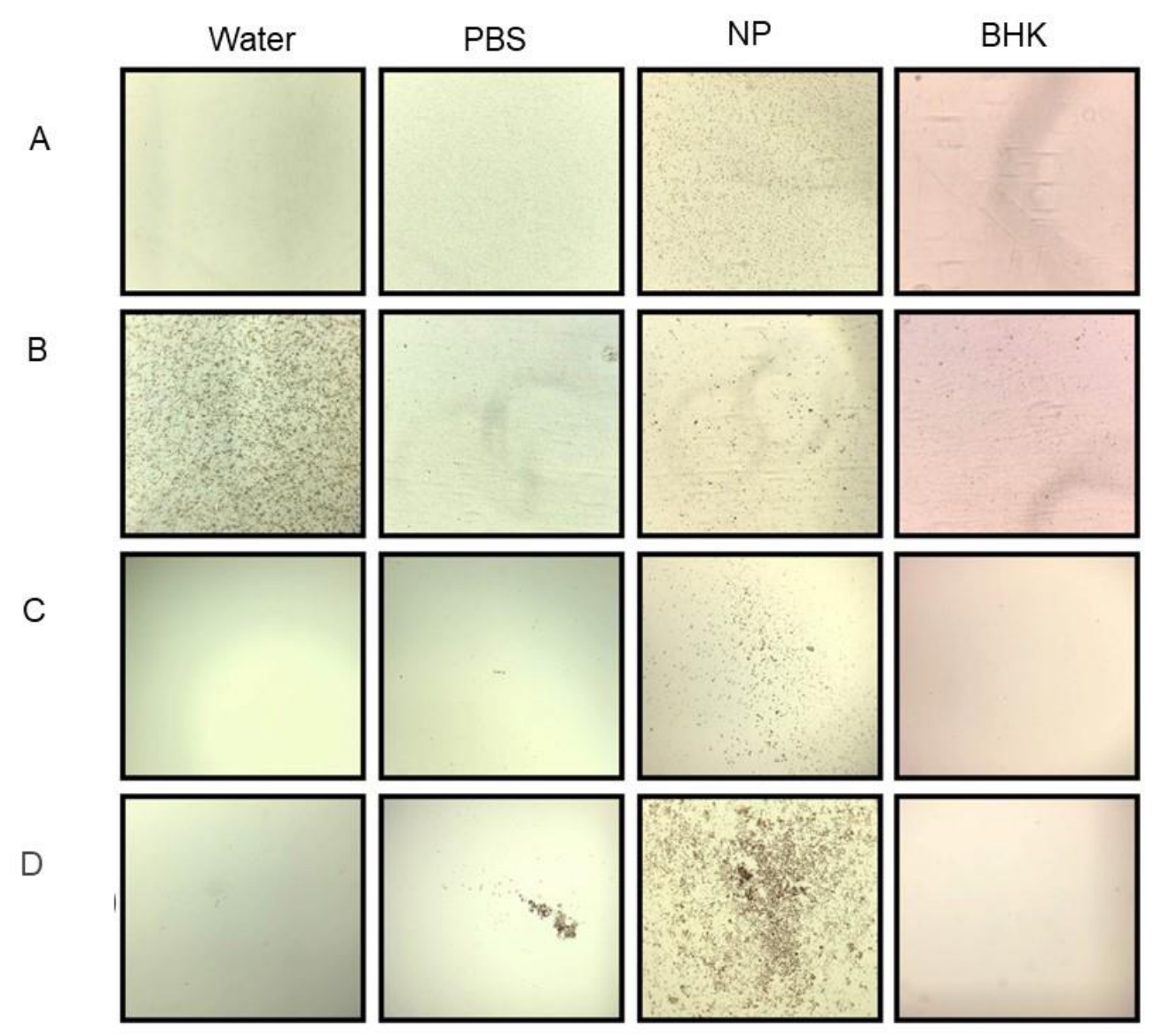

Figure 11: Representative white light microcopy images at 10x magnification after incubation of $5 \times 10^{10} \mathrm{nps} / \mathrm{mL}$ A) AuNRs-mSiO 2 -polymer-LRSH at $+50 \mathrm{mV}$, B) AuNRs- $\mathrm{mSiO}_{2}$-polymer-LRSH at $+35 \mathrm{mV}$, C) AuNR-SOA-PC:PE-RGD:PE-LRSH-HT at $-4.8 \mathrm{mV}$ and D) AuNR-SOA-PC:PERGD:PE-LRSH:DOTAP-HT at $-6.6 \mathrm{mV}$ in water, $10 \mathrm{mM}$ PBS $\mathrm{pH}$ 7.4, NP serum free media and BHK DMEM media for $24 \mathrm{~h}$. AuNRs show up as accumulations of small black granules. 


\section{Cytotoxicity Studies}

Despite the great potential of AuNRs for diagnostic, drug delivery, imaging, and therapeutic applications their possible toxicity has become a concern that must be addressed if we are to advance them for in vivo applications. That is, their safety and biocompatibility are of paramount importance if they are to be used for stem cell labeling or imaging agents in ophthalmology applications. Therefore, we carried out a comparative study of the effect of the surface coatings on the cytotoxicity of the two subtypes of AuNRs. Briefly, 10,000 BHK cells were exposed to varying concentrations $5.0 \times 10^{8}$ to $5.0 \times 10^{10} \mathrm{AuNRs} / \mathrm{mL}$ for $24 \mathrm{~h}$. The AuNRs-mSiO 2 -polymer-Cy3 (\#1), AuNRs-mSiO 2 -polymer-LRSH (\#3), AuNR-SOA-PC:PE-LRSH:DOTAP-HT (\#8), and AuNRSOA-PC:PE-RGD-PE:LRSH:DOTAP-HT (\#10) decreased the cell viability to $80 \pm 8 \%$ with increasing concentrations of AuNRs indicating mild toxicity. In contrast, the AuNR-SOA-PC:PERGD:PE-LRSH-HT (\#9) showed very minimal cell death $(92 \pm 7 \%)$ indicating this platform with the least negative charge is the most biocompatible with increasing concentrations. Although the surface chemistry of the hybrid lipid-coated AuNRs is different and the shape of the nanomaterials is rod-shaped, the results are consistent with previous in vivo zebrafish embryonic studies that show when spherical gold or triangular-plate silver nanomaterials coated with a membraneanchored by a long-chained hydrophobic thiol the nanomaterials are biocompatible. ${ }^{110,112}$ These studies also suggest that nanoparticles with neutral or slightly negative charge might be more appropriate for long-term cell viability of stem cell-derived therapeutic cells. 


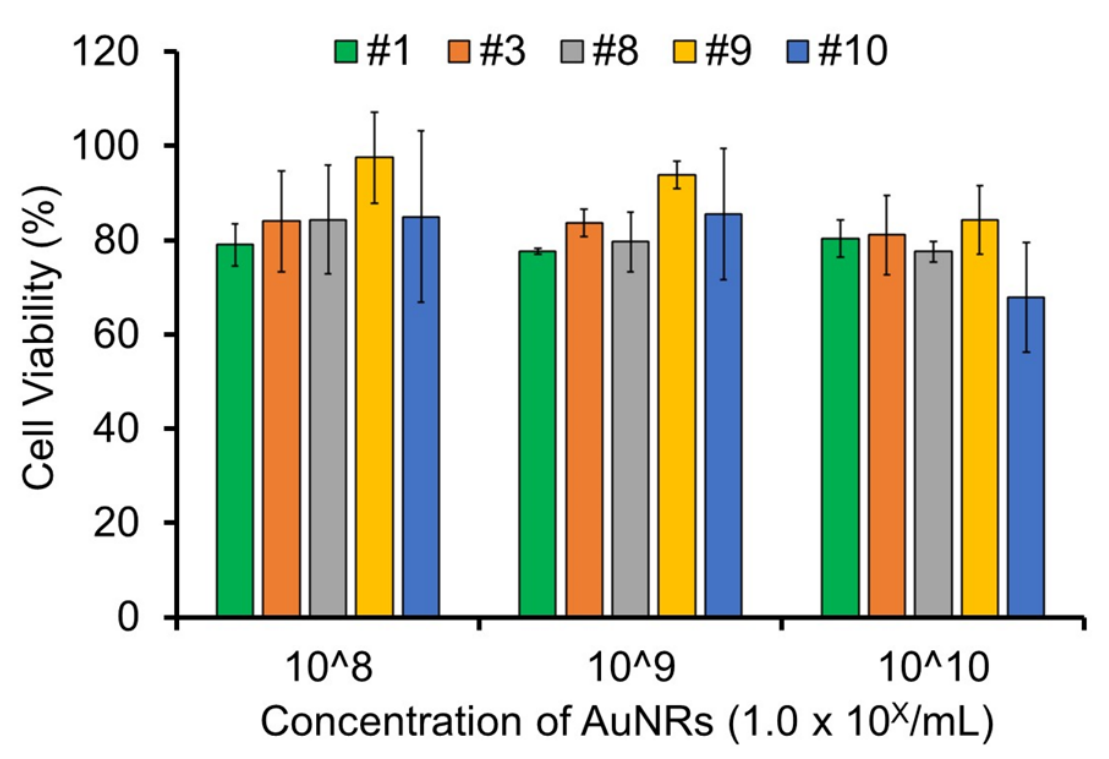

Figure 12: Viability of 10,000 BHK cells exposed to AuNRs with different coatings and surface charge. The cells were exposed to varying concentrations of AuNRs from $5.0 \times 10^{8}$ to $5.0 \times 10^{10}$ of coated AuNRs listed in Table 1 (\#1, \#3, \#8, and \#10) for $24 \mathrm{~h}$. The cell viability was measured by MTS assay. The results were calculated as percentages relative to the control of untreated cells. The experiment was repeated 3 times for each of the coated AuNR sample.

\section{Conclusion}

Here we have evaluated the stability, cellular uptake, localization, and toxicity of two different types of AuNRs with different coatings, a $\mathrm{mSiO}_{2}$ with a polymer layer and hybrid lipid membrane coating, with three different cell types. Two of these cell lines are stem cell-derived therapeutic cells that are used in stem cell replacement strategies in clinical trials. Confocal and TEM microscopy showed that both subtypes of AuNRs readily internalized into the cytoplasm of BHK, RPE, and NP cell lines. Based on fluorescence studies a greater uptake of hybrid lipid-coated AuNRs is observed with cationic ligands such as DOTAP or cell-penetrating ligands such as RGD is incorporated into the membrane platform. In contrast, while a greater amount of positively charged AuNRs- $\mathrm{mSiO}_{2}$-polymer-LRSH type nanoparticles are taken up in BHK and RPE cell lines compared to hybrid lipid-coated AuNRs and are found to exist as aggregates in the cytoplasm of the cells. Stability studies in cell media containing a variety of proteins and small molecules show 
that the surface charge plays a significant role in nanoparticle stability. All the positively charged AuNRs-mSiO 2 -polymer-LRSH nanoparticles show significant nanoparticle-nanoparticle interaction in water and $10 \mathrm{mM}$ PBS buffer at $\mathrm{pH}$ 7.4, which is mostly due to the "sticky" nature of the polymer layer and this interaction is enhanced greatly in the presence of media with small molecules and proteins. The slightly negatively charged hybrid lipid-coated AuNRs show greater stability in cell media and minimal nanoparticle-nanoparticle interactions indicating they are less susceptible to protein-nanoparticle interaction, with the only exception being the NP media where some aggregation is observed. This is not surprising since other positively charged nanoparticles are known to interact with proteins compared to negative or neutral nanoparticles. In the presence of most of the AuNR subtypes, the cell viability was $80 \%$, except for the least negatively charged hybrid lipid-coated AuNR, AuNR-SOA-PC:PE-RGD:PE-LRSH-HT (\#9), which had a cell viability of $92 \%$. While it was a bit surprising that the AuNRs-mSiO 2 -polymer-LRSH nanoparticles that even with the significant level of aggregation observed that a greater number of these nanoparticles are internalized, and that significant toxicity are not observed. This study also confirms that the formation of a protein corona can mask the nanomaterials to minimize toxicity. It is therefore likely that the uptake mechanism for both subtypes of AuNRs is different and that the protein corona formed on positively and slightly negative AuNRs is different for both platforms. Overall, our studies show that both AuNRs-mSiO 2 -polymer-LRSH and hybrid lipid membrane-coated AuNRs are good platforms for enhancing cellular uptake of AuNRs into stem cell-derived therapeutic cells without significantly disrupting cell health. However, the design features of the hybrid lipid membrane platform are versatile for easily producing libraries of AuNRs with varying membrane compositions that allow for controlling the charge, concentration of targeting, or drugs that can be cleaved from the nanoparticle surface. The flexible approach to tuning the surface chemistry of the AuNRs with the hybrid lipid membrane strategy provides 
opportunities for us to explore targeting specific cells in the eye or permanently label the cells to prevent nanoparticle migration out of the desired cell that we want to track visually with various imaging modalities. We expect that future investigations will demonstrate that these nanomaterials will be safe nanoparticle stem cell labels that will allow us to track therapeutic stem cells in vivo to investigate their safety and efficacy.

\section{References}

1. Sim, S.; Wong, N. K., Nanotechnology and its use in imaging and drug delivery (Review). Biomed Rep 2021, 14 (5), 42.

2. Sindhwani, S.; Chan, W. C. W., Nanotechnology for modern medicine: next step towards clinical translation. Journal of Internal Medicine n/a (n/a).

3. Chintagunta, A. D.; M, S. K.; Nalluru, S.; N. S, S. K., Nanotechnology: an emerging approach to combat COVID-19. Emergent Materials 2021, 4 (1), 119-130.

4. Luo, M.-X.; Hua, S.; Shang, Q.-Y., Application of nanotechnology in drug delivery systems for respiratory diseases (Review). Mol Med Rep 2021, 23 (5), 325.

5. Gottardo, S.; Mech, A.; Drbohlavová, J.; Małyska, A.; Bøwadt, S.; Riego Sintes, J.; Rauscher, H., Towards safe and sustainable innovation in nanotechnology: State-of-play for smart nanomaterials. NanoImpact 2021, 21, 100297.

6. Chanan, D. S.; Zhengkai, H.; Xiao, W.; Jia, L., Functional Nanomaterial-Enabled Synthetic Biology. Nano Futures 2021.

7. Patra, J. K.; Das, G.; Fraceto, L. F.; Campos, E. V. R.; Rodriguez-Torres, M. D. P.; Acosta-Torres, L. S.; Diaz-Torres, L. A.; Grillo, R.; Swamy, M. K.; Sharma, S.; Habtemariam, S.; Shin, H. S., Nano based drug delivery systems: recent developments and future prospects. $J$ Nanobiotechnology 2018, 16 (1), 71.

8. Su, H.; Wang, Y.; Gu, Y.; Bowman, L.; Zhao, J.; Ding, M., Potential applications and human biosafety of nanomaterials used in nanomedicine. Journal of applied toxicology : JAT 2018, 38 (1), 3-24.

9. $\quad$ Rizzo, L. Y.; Theek, B.; Storm, G.; Kiessling, F.; Lammers, T., Recent progress in nanomedicine: therapeutic, diagnostic and theranostic applications. Current opinion in biotechnology 2013, 24 (6), 1159-66.

10. Kalishwaralal, K.; Barathmanikanth, S.; Pandian, S. R.; Deepak, V.; Gurunathan, S., Silver nano - a trove for retinal therapies. Journal of controlled release : official journal of the Controlled Release Society 2010, 145 (2), 76-90.

11. Wilson, A. M.; Mazzaferri, J.; Bergeron, É.; Patskovsky, S.; Marcoux-Valiquette, P.; Costantino, S.; Sapieha, P.; Meunier, M., In Vivo Laser-Mediated Retinal Ganglion Cell Optoporation Using KV1.1 Conjugated Gold Nanoparticles. Nano Letters 2018, 18 (11), 6981-6988.

12. Scheive, M.; Yazdani, S.; Hajrasouliha, A. R., The utility and risks of therapeutic nanotechnology in the retina. Therapeutic Advances in Ophthalmology 2021, 13, 25158414211003381. 
13. Tsai, C. H.; Wang, P. Y.; Lin, I. C.; Huang, H.; Liu, G. S.; Tseng, C. L., Ocular Drug Delivery: Role of Degradable Polymeric Nanocarriers for Ophthalmic Application. Int J Mol Sci 2018, 19 (9).

14. Rong, X.; Ji, Y.; Zhu, X.; Yang, J.; Qian, D.; Mo, X.; Lu, Y., Neuroprotective effect of insulinloaded chitosan nanoparticles/PLGA-PEG-PLGA hydrogel on diabetic retinopathy in rats. International journal of nanomedicine 2019, 14, 45-55.

15. Mitra, R. N.; Han, Z.; Merwin, M.; Al Taai, M.; Conley, S. M.; Naash, M. I., Synthesis and characterization of glycol chitosan DNA nanoparticles for retinal gene delivery. ChemMedChem 2014, 9 (1), 189-96.

16. Pandit, J.; Sultana, Y.; Aqil, M., Chitosan-coated PLGA nanoparticles of bevacizumab as novel drug delivery to target retina: optimization, characterization, and in vitro toxicity evaluation. Artificial cells, nanomedicine, and biotechnology 2017, 45 (7), 1397-1407.

17. Martens, T. F.; Peynshaert, K.; Nascimento, T. L.; Fattal, E.; Karlstetter, M.; Langmann, T.; Picaud, S.; Demeester, J.; De Smedt, S. C.; Remaut, K.; Braeckmans, K., Effect of hyaluronic acid-binding to lipoplexes on intravitreal drug delivery for retinal gene therapy. European journal of pharmaceutical sciences : official journal of the European Federation for Pharmaceutical Sciences 2017, 103, 27-35.

18. Yavuz, B.; Pehlivan, S. B.; Vural, İ.; Ünlü, N., In Vitro/In Vivo Evaluation of Dexamethasone-PAMAM Dendrimer Complexes for Retinal Drug Delivery. Journal of pharmaceutical sciences 2015, 104 (11), 3814-3823.

19. Battaglia, L.; Serpe, L.; Foglietta, F.; Muntoni, E.; Gallarate, M.; Del Pozo Rodriguez, A.; Solinis, M. A., Application of lipid nanoparticles to ocular drug delivery. Expert opinion on drug delivery 2016, 13 (12), 1743-1757.

20. Seyfoddin, A.; Shaw, J.; Al-Kassas, R., Solid lipid nanoparticles for ocular drug delivery. Drug delivery 2010, 17 (7), 467-89.

21. Apaolaza, P. S.; Del Pozo-Rodríguez, A.; Solinís, M. A.; Rodríguez, J. M.; Friedrich, U.; Torrecilla, J.; Weber, B. H.; Rodríguez-Gascón, A., Structural recovery of the retina in a retinoschisin-deficient mouse after gene replacement therapy by solid lipid nanoparticles. Biomaterials 2016, 90, 40-9.

22. Sheikpranbabu, S.; Kalishwaralal, K.; Lee, K. J.; Vaidyanathan, R.; Eom, S. H.; Gurunathan, S., The inhibition of advanced glycation end-products-induced retinal vascular permeability by silver nanoparticles. Biomaterials 2010, 31 (8), 2260-71.

23. Masse, F.; Ouellette, M.; Lamoureux, G.; Boisselier, E., Gold nanoparticles in ophthalmology. Medicinal research reviews 2019, 39 (1), 302-327.

24. Wu, L.; Acón, D.; Wu, A.; Wu, M., Vascular endothelial growth factor inhibition and proliferative diabetic retinopathy, a changing treatment paradigm? Taiwan journal of ophthalmology 2019, 9 (4), 216-223.

25. Jo, D. H.; Kim, J. H.; Yu, Y. S.; Lee, T. G.; Kim, J. H., Antiangiogenic effect of silicate nanoparticle on retinal neovascularization induced by vascular endothelial growth factor. Nanomedicine : nanotechnology, biology, and medicine 2012, 8 (5), 784-91.

26. Joseph, R. R.; Venkatraman, S. S., Drug delivery to the eye: what benefits do nanocarriers offer? Nanomedicine : nanotechnology, biology, and medicine 2017, 12 (6), 683-702.

27. Jiang, S.; Franco, Y. L.; Zhou, Y.; Chen, J., Nanotechnology in retinal drug delivery. International journal of ophthalmology 2018, 11 (6), 1038-1044.

28. Yamada, N.; Olsen, T. W., Routes for Drug Delivery to the Retina: Topical, Transscleral, Suprachoroidal and Intravitreal Gas Phase Delivery. Developments in ophthalmology 2016, 55, 71-83. 
29. Murray, P. A.; Woolf, A. S., Using stem and progenitor cells to recapitulate kidney development and restore renal function. Current opinion in organ transplantation 2014, 19 (2), 140-4.

30. Hannoun, Z.; Steichen, C.; Dianat, N.; Weber, A.; Dubart-Kupperschmitt, A., The potential of induced pluripotent stem cell derived hepatocytes. Journal of hepatology 2016, 65 (1), 182-199.

31. Kemp, P., History of regenerative medicine: looking backwards to move forwards. Regenerative medicine 2006, 1 (5), 653-69.

32. Stone, E. M., A very effective treatment for neovascular macular degeneration. The New England journal of medicine 2006, 355 (14), 1493-5.

33. Ricles, L. M.; Nam, S. Y.; Treviño, E. A.; Emelianov, S. Y.; Suggs, L. J., A Dual Gold Nanoparticle System for Mesenchymal Stem Cell Tracking. Journal of materials chemistry. B 2014, 2 (46), 8220-8230.

34. Chemla, Y.; Betzer, O.; Markus, A.; Farah, N.; Motiei, M.; Popovtzer, R.; Mandel, Y., Gold nanoparticles for multimodal high-resolution imaging of transplanted cells for retinal replacement therapy. Nanomedicine : nanotechnology, biology, and medicine 2019, 14 (14), 1857-1871.

35. Mulder, W. J.; Strijkers, G. J.; Habets, J. W.; Bleeker, E. J.; van der Schaft, D. W.; Storm, G.; Koning, G. A.; Griffioen, A. W.; Nicolay, K., MR molecular imaging and fluorescence microscopy for identification of activated tumor endothelium using a bimodal lipidic nanoparticle. FASEB journal : official publication of the Federation of American Societies for Experimental Biology 2005, 19 (14), 2008-10.

36. Rao, J.; Dragulescu-Andrasi, A.; Yao, H., Fluorescence imaging in vivo: recent advances. Current opinion in biotechnology 2007, 18 (1), 17-25.

37. Yang, X.; Stein, E. W.; Ashkenazi, S.; Wang, L. V., Nanoparticles for photoacoustic imaging. Wiley interdisciplinary reviews. Nanomedicine and nanobiotechnology 2009, 1 (4), 360-8.

38. de la Zerda, A.; Kim, J. W.; Galanzha, E. I.; Gambhir, S. S.; Zharov, V. P., Advanced contrast nanoagents for photoacoustic molecular imaging, cytometry, blood test and photothermal theranostics. Contrast media \& molecular imaging 2011, 6 (5), 346-69.

39. Sanvicens, N.; Marco, M. P., Multifunctional nanoparticles--properties and prospects for their use in human medicine. Trends in biotechnology 2008, 26 (8), 425-33.

40. Scarfe, L.; Brillant, N.; Kumar, J. D.; Ali, N.; Alrumayh, A.; Amali, M.; Barbellion, S.; Jones, V.; Niemeijer, M.; Potdevin, S.; Roussignol, G.; Vaganov, A.; Barbaric, I.; Barrow, M.; Burton, N. C.; Connell, J.; Dazzi, F.; Edsbagge, J.; French, N. S.; Holder, J.; Hutchinson, C.; Jones, D. R.; Kalber, T.; Lovatt, C.; Lythgoe, M. F.; Patel, S.; Patrick, P. S.; Piner, J.; Reinhardt, J.; Ricci, E.; Sidaway, J.; Stacey, G. N.; Starkey Lewis, P. J.; Sullivan, G.; Taylor, A.; Wilm, B.; Poptani, H.; Murray, P.; Goldring, C. E. P.; Park, B. K., Preclinical imaging methods for assessing the safety and efficacy of regenerative medicine therapies. npj Regenerative Medicine 2017, 2 (1), 28.

41. Tucker-Schwartz, J. M.; Hong, T.; Colvin, D. C.; Xu, Y.; Skala, M. C., Dual-modality photothermal optical coherence tomography and magnetic-resonance imaging of carbon nanotubes. Optics letters 2012, 37 (5), 872-4.

42. Oldenburg, A.; Toublan, F.; Suslick, K.; Wei, A.; Boppart, S., Magnetomotive contrast for in vivo optical coherence tomography. Optics express 2005, 13 (17), 6597-614.

43. Kirillin, M. Y.; Sergeeva, E. A.; Agrba, P. D.; Krainov, A. D.; Ezhov, A. A.; Shuleiko, D. V.; Kashkarov, P. K.; Zabotnov, S. V., Laser-ablated silicon nanoparticles: optical properties and perspectives in optical coherence tomography. Laser Physics 2015, 25 (7), 075604.

44. Jain, P. K.; Lee, K. S.; El-Sayed, I. H.; El-Sayed, M. A., Calculated absorption and scattering properties of gold nanoparticles of different size, shape, and composition: applications in biological imaging and biomedicine. The journal of physical chemistry. B 2006, 110 (14), 723848. 
45. Link, S.; Mohamed, M. B.; El-Sayed, M. A., Simulation of the Optical Absorption Spectra of Gold Nanorods as a Function of Their Aspect Ratio and the Effect of the Medium Dielectric Constant. The Journal of Physical Chemistry B 1999, 103 (16), 3073-3077.

46. Wang, L.; Jacques, S. L.; Zheng, L., MCML--Monte Carlo modeling of light transport in multilayered tissues. Computer methods and programs in biomedicine 1995, 47 (2), 131-46.

47. Yguerabide, J.; Yguerabide, E. E., Light-Scattering Submicroscopic Particles as Highly Fluorescent Analogs and Their Use as Tracer Labels in Clinical and Biological Applications: I. Theory. Analytical Biochemistry 1998, 262 (2), 137-156.

48. Skala, M. C.; Crow, M. J.; Wax, A.; Izatt, J. A., Photothermal optical coherence tomography of epidermal growth factor receptor in live cells using immunotargeted gold nanospheres. Nano Lett 2008, 8 (10), 3461-7.

49. Loo, C.; Lin, A.; Hirsch, L.; Lee, M. H.; Barton, J.; Halas, N.; West, J.; Drezek, R., Nanoshellenabled photonics-based imaging and therapy of cancer. Technology in cancer research \& treatment 2004, 3 (1), 33-40.

50. Nahas, A.; Varna, M.; Fort, E.; Boccara, A. C., Detection of plasmonic nanoparticles with full field-OCT: optical and photothermal detection. Biomed Opt Express 2014, 5 (10), 3541-6.

51. Gobin, A. M.; Lee, M. H.; Halas, N. J.; James, W. D.; Drezek, R. A.; West, J. L., Near-Infrared Resonant Nanoshells for Combined Optical Imaging and Photothermal Cancer Therapy. Nano Letters 2007, 7 (7), 1929-1934.

52. Ponce de León, Y.; Pichardo-Molina, J. L.; Alcalá Ochoa, N.; Luna-Moreno, D., Contrast Enhancement of Optical Coherence Tomography Images Using Branched Gold Nanoparticles. Journal of Nanomaterials 2012, 2012, 571015.

53. Si, P.; Yuan, E.; Liba, O.; Winetraub, Y.; Yousefi, S.; SoRelle, E. D.; Yecies, D. W.; Dutta, R.; de la Zerda, A., Gold Nanoprisms as Optical Coherence Tomography Contrast Agents in the Second Near-Infrared Window for Enhanced Angiography in Live Animals. ACS Nano 2018, 12 (12), 11986-11994.

54. Oldenburg, A.; Zweifel, D. A.; Xu, C.; Wei, A.; Boppart, S. A. In Characterization of plasmonresonant gold nanorods as near-infrared optical contrast agents investigated using a doubleintegrating sphere system, SPIE BiOS, SPIE: 2005; p 11.

55. Liba, O.; SoRelle, E. D.; Sen, D.; de la Zerda, A., Contrast-enhanced optical coherence tomography with picomolar sensitivity for functional in vivo imaging. Sci Rep 2016, 6, 23337.

56. Jia, Y.; Liu, G.; Gordon, A. Y.; Gao, S. S.; Pechauer, A. D.; Stoddard, J.; McGill, T. J.; Jayagopal, A.; Huang, D., Spectral fractionation detection of gold nanorod contrast agents using optical coherence tomography. Optics express 2015, 23 (4), 4212-25.

57. Oldenburg, A. L.; Chhetri, R. K.; Cooper, J. M.; Wu, W. C.; Troester, M. A.; Tracy, J. B., Motility, autocorrelation-, and polarization-sensitive optical coherence tomography discriminates cells and gold nanorods within 3D tissue cultures. Optics letters 2013, 38 (15), 2923-6.

58. Troutman, T. S.; Barton, J. K.; Romanowski, M., Optical coherence tomography with plasmon resonant nanorods of gold. Optics letters 2007, 32 (11), 1438-40.

59. Huang, Y.; Li, M.; Huang, D.; Qiu, Q.; Lin, W.; Liu, J.; Yang, W.; Yao, Y.; Yan, G.; Qu, N.; Tuchin, V. V.; Fan, S.; Liu, G.; Zhao, Q.; Chen, X., Depth-Resolved Enhanced Spectral-Domain OCT Imaging of Live Mammalian Embryos Using Gold Nanoparticles as Contrast Agent. Small (Weinheim an der Bergstrasse, Germany) 2019, 15 (35), 1902346.

60. Song, H. B.; Wi, J. S.; Jo, D. H.; Kim, J. H.; Lee, S. W.; Lee, T. G.; Kim, J. H., Intraocular application of gold nanodisks optically tuned for optical coherence tomography: inhibitory effect on retinal neovascularization without unbearable toxicity. Nanomedicine : nanotechnology, biology, and medicine 2017, 13 (6), 1901-1911. 
61. Agrawal, A.; Huang, S.; Wei Haw Lin, A.; Lee, M. H.; Barton, J. K.; Drezek, R. A.; Pfefer, T. J., Quantitative evaluation of optical coherence tomography signal enhancement with gold nanoshells. Journal of biomedical optics 2006, 11 (4), 041121.

62. Cang, H.; Sun, T.; Li, Z. Y.; Chen, J.; Wiley, B. J.; Xia, Y.; Li, X., Gold nanocages as contrast agents for spectroscopic optical coherence tomography. Optics letters 2005, 30 (22), 3048-50.

63. Mondal, I.; Raj, S.; Roy, P.; Poddar, R., Silver nanoparticles (AgNPs) as a contrast agent for imaging of animal tissue using swept-source optical coherence tomography (SSOCT). Laser Physics 2017, 28 (1), 015601.

64. Olga, B.; Alexey, P. P.; Alexander, V. B.; Artur, P.; Matti, T. K.; Krisztián, K.; Vladimir, B.; Nikolai, K.; Seppo, V.; Valery, V. T., Optical properties of plasmon-resonant bare and silicacoated nanostars used for cell imaging. J Biomed Opt 2015, 20 (7), 1-11.

65. Xu, Y.; Zhou, B.; Zhuang, C.; Zhou, J.; Chen, H.; Deng, S., High-Aspect-Ratio Plasmonic Heterostructures for In Vivo Enhanced Optical Coherence Tomography Imaging in the Second Near-Infrared Biological Window. Advanced Optical Materials n/a (n/a), 2000384.

66. 2015;31(4)., B. S. M. O. S. a. A. C. o. S. a. S. S. C. s. N. O. J. C.

67. Zhang, Y. Q.; Wu, G. Y.; Wei, H. J.; Guo, Z. Y.; Yang, H. Q.; He, Y. H.; Xie, S. S.; Liu, Y., Effect of differently sized nanoparticles' accumulation on the optical properties ofex vivonormal and adenomatous human colon tissue with OCT imaging and diffuse reflectance spectra. Laser Physics Letters 2014, 11 (8), 085901.

68. Accomasso, L.; Gallina, C.; Turinetto, V.; Giachino, C., Stem Cell Tracking with Nanoparticles for Regenerative Medicine Purposes: An Overview. Stem Cells International 2016, 2016, 7920358.

69. Wu, S.-Q.; Chi, C.-W.; Yang, C.-X.; Yan, X.-P., Penetrating Peptide-Bioconjugated Persistent Nanophosphors for Long-Term Tracking of Adipose-Derived Stem Cells with Superior Signal-toNoise Ratio. Analytical Chemistry 2016, 88 (7), 4114-4121.

70. Barrow, M.; Taylor, A.; Murray, P.; Rosseinsky, M. J.; Adams, D. J., Design considerations for the synthesis of polymer coated iron oxide nanoparticles for stem cell labelling and tracking using MRI. Chemical Society Reviews 2015, 44 (19), 6733-6748.

71. Comenge, J.; Fragueiro, O.; Sharkey, J.; Taylor, A.; Held, M.; Burton, N. C.; Park, B. K.; Wilm, B.; Murray, P.; Brust, M.; Lévy, R., Preventing Plasmon Coupling between Gold Nanorods Improves the Sensitivity of Photoacoustic Detection of Labeled Stem Cells in Vivo. ACS Nano 2016, 10 (7), 7106-7116.

72. Li, W.; Chen, X., Gold nanoparticles for photoacoustic imaging. Nanomedicine : nanotechnology, biology, and medicine 2015, 10 (2), 299-320.

73. Tkaczyk, T. S.; Rahman, M.; Mack, V.; Sokolov, K.; Rogers, J. D.; Richards-Kortum, R.; Descour, M. R., High resolution, molecular-specific, reflectance imaging in optically dense tissue phantoms with structured-illumination. Optics express 2004, 12 (16), 3745-3758.

74. Truffi, M.; Fiandra, L.; Sorrentino, L.; Monieri, M.; Corsi, F.; Mazzucchelli, S., Ferritin nanocages: A biological platform for drug delivery, imaging and theranostics in cancer. Pharmacological research 2016, 107, 57-65.

75. Oh, E.; Delehanty, J. B.; Sapsford, K. E.; Susumu, K.; Goswami, R.; Blanco-Canosa, J. B.; Dawson, P. E.; Granek, J.; Shoff, M.; Zhang, Q.; Goering, P. L.; Huston, A.; Medintz, I. L., Cellular Uptake and Fate of PEGylated Gold Nanoparticles Is Dependent on Both Cell-Penetration Peptides and Particle Size. ACS Nano 2011, 5 (8), 6434-6448.

76. Prow, T. W., Toxicity of nanomaterials to the eye. Wiley interdisciplinary reviews. Nanomedicine and nanobiotechnology 2010, 2 (4), 317-33. 
77. Khan, H. A.; Alamery, S.; Ibrahim, K. E.; El-Nagar, D. M.; Al-Harbi, N.; Rusop, M.; Alrokayan, S. H., Size and time-dependent induction of proinflammatory cytokines expression in brains of mice treated with gold nanoparticles. Saudi Journal of Biological Sciences 2019, 26 (3), 625-631.

78. Chithrani, B. D.; Ghazani, A. A.; Chan, W. C., Determining the size and shape dependence of gold nanoparticle uptake into mammalian cells. Nano Lett 2006, 6 (4), 662-8.

79. Chithrani, B. D.; Chan, W. C., Elucidating the mechanism of cellular uptake and removal of protein-coated gold nanoparticles of different sizes and shapes. Nano Lett 2007, 7 (6), 1542-50.

80. Jiang, W.; Kim, B. Y.; Rutka, J. T.; Chan, W. C., Nanoparticle-mediated cellular response is sizedependent. Nat Nanotechnol. 2008 Mar;3(3):145-50. doi: 10.1038/nnano.2008.30. Epub 2008 Mar 2.

81. Champion, J. A.; Walker, A.; Mitragotri, S., Role of particle size in phagocytosis of polymeric microspheres. Pharm Res 2008, 25 (8), 1815-21.

82. Moreira, J. N.; Santos, A.; Moura, V.; Pedroso de Lima, M. C.; Simoes, S., Non-viral lipid-based nanoparticles for targeted cancer systemic gene silencing. J Nanosci Nanotechnol 2008, 8 (5), 2187-204.

83. Lin, Q.; Chen, J.; Zhang, Z.; Zheng, G., Lipid-based nanoparticles in the systemic delivery of siRNA. Nanomedicine 2014, 9 (1), 105-20.

84. Miller, A. D., Lipid-Based Nanoparticles in Cancer Diagnosis and Therapy. Journal of Drug Delivery 2013, 2013, 9.

85. Puri, A.; Loomis, K.; Smith, B.; Lee, J.-H.; Yavlovich, A.; Heldman, E.; Blumenthal, R., LipidBased Nanoparticles as Pharmaceutical Drug Carriers: From Concepts to Clinic. Critical reviews in therapeutic drug carrier systems 2009, 26 (6), 523-580.

86. He, C.; Hu, Y.; Yin, L.; Tang, C.; Yin, C., Effects of particle size and surface charge on cellular uptake and biodistribution of polymeric nanoparticles. Biomaterials 2010, 31 (13), 3657-66.

87. Yang, K.; Mesquita, B.; Horvatovich, P.; Salvati, A., Tuning liposome composition to modulate corona formation in human serum and cellular uptake. Acta biomaterialia 2020, 106, 314-327.

88. Gessner, I.; Klimpel, A.; Klußmann, M.; Neundorf, I.; Mathur, S., Interdependence of charge and secondary structure on cellular uptake of cell penetrating peptide functionalized silica nanoparticles. Nanoscale Advances 2020, 2 (1), 453-462.

89. Cardoso, R. M.; Deda, D. K.; Toma, S. H.; Baptista, M. S.; Araki, K., Beyond electrostatic interactions: Ligand shell modulated uptake of bis-conjugated iron oxide nanoparticles by cells. Colloids and Surfaces B: Biointerfaces 2020, 186, 110717.

90. Dey, A.; Stenberg, J.; Dandekar, P.; Jain, R., A combinatorial study of experimental analysis and mathematical modeling: How do chitosan nanoparticles deliver therapeutics into cells? Carbohydrate Polymers 2020, 229, 115437.

91. Park, S.; Sherwood, J. A.; Hauser, R. M.; Antone, A. J.; Beswick, B. T.; Lubin, F. D.; Bao, Y.; Kim, Y., Surface Effects of Ultrasmall Iron Oxide Nanoparticles on Cellular Uptake, Proliferation, and Multipotency of Neural Stem Cells. ACS Applied Nano Materials 2020, 3 (2), 1542-1552.

92. Nelemans, L. C. G., L. Drug Delivery with Polymeric Nanocarriers-Cellular Uptake Mechanisms. Materials 2020, 13, 366.

93. Donahue, N. D.; Acar, H.; Wilhelm, S., Concepts of nanoparticle cellular uptake, intracellular trafficking, and kinetics in nanomedicine. Advanced drug delivery reviews 2019, 143, 68-96.

94. Encinas, N.; Angulo, M.; Astorga, C.; Colilla, M.; Izquierdo-Barba, I.; Vallet-Regí, M., Mixedcharge pseudo-zwitterionic mesoporous silica nanoparticles with low-fouling and reduced cell uptake properties. Acta biomaterialia 2019, 84, 317-327.

95. Jin, Q.; Deng, Y.; Chen, X.; Ji, J., Rational Design of Cancer Nanomedicine for Simultaneous Stealth Surface and Enhanced Cellular Uptake. ACS Nano 2019, 13 (2), 954-977. 
96. Van Lehn, R. C.; Alexander-Katz, A., Energy landscape for the insertion of amphiphilic nanoparticles into lipid membranes: A computational study. PLoS One 2019, 14 (1), e0209492e0209492.

97. Fröhlich, E., The role of surface charge in cellular uptake and cytotoxicity of medical nanoparticles. International journal of nanomedicine 2012, 7, 5577-5591.

98. Wei, X.; Shao, B.; He, Z.; Ye, T.; Luo, M.; Sang, Y.; Liang, X.; Wang, W.; Luo, S.; Yang, S.; Zhang, S.; Gong, C.; Gou, M.; Deng, H.; Zhao, Y.; Yang, H.; Deng, S.; Zhao, C.; Yang, L.; Qian, Z.; Li, J.; Sun, X.; Han, J.; Jiang, C.; Wu, M.; Zhang, Z., Cationic nanocarriers induce cell necrosis through impairment of $\mathrm{Na}+\mathrm{K}+-\mathrm{ATPase}$ and cause subsequent inflammatory response. Cell Research 2015, 25 (2), 237-253.

99. Weiss, M.; Fan, J.; Claudel, M.; Sonntag, T.; Didier, P.; Ronzani, C.; Lebeau, L.; Pons, F., Density of surface charge is a more predictive factor of the toxicity of cationic carbon nanoparticles than zeta potential. Journal of Nanobiotechnology 2021, 19 (1), 5.

100. McConnell, K. I.; Shamsudeen, S.; Meraz, I. M.; Mahadevan, T. S.; Ziemys, A.; Rees, P.; Summers, H. D.; Serda, R. E., Reduced Cationic Nanoparticle Cytotoxicity Based on Serum Masking of Surface Potential. Journal of biomedical nanotechnology 2016, 12 (1), 154-64.

101. Doorley, G. W.; Payne, C. K., Cellular binding of nanoparticles in the presence of serum proteins. Chem Commun 2011, 47 (1), 466-8.

102. Doorley, G. W.; Payne, C. K., Nanoparticles act as protein carriers during cellular internalization. Chem Commun 2012, 48 (24), 2961-3.

103. Cedervall, T.; Lynch, I.; Foy, M.; Berggard, T.; Donnelly, S. C.; Cagney, G.; Linse, S.; Dawson, K. A., Detailed identification of plasma proteins adsorbed on copolymer nanoparticles. Angew Chem Int Ed Engl 2007, 46 (30), 5754-6.

104. Lesniak, A.; Campbell, A.; Monopoli, M. P.; Lynch, I.; Salvati, A.; Dawson, K. A., Serum heat inactivation affects protein corona composition and nanoparticle uptake. Biomaterials 2010, 31 (36), 9511-8.

105. Karakoçak, B. B.; Raliya, R.; Davis, J. T.; Chavalmane, S.; Wang, W.-N.; Ravi, N.; Biswas, P., Biocompatibility of gold nanoparticles in retinal pigment epithelial cell line. Toxicology in Vitro 2016, 37, 61-69.

106. Mackiewicz, M. R.; Hodges, H. L.; Reed, S. M., C-Reactive Protein Induced Rearrangement of Phosphatidylcholine on Nanoparticle Mimics of Lipoprotein Particles. The Journal of Physical Chemistry B 2010, 114 (16), 5556-5562.

107. Sitaula, S.; Mackiewicz, M. R.; Reed, S. M., Gold nanoparticles become stable to cyanide etch when coated with hybrid lipid bilayers. Chemical Communications 2008, (26), 3013-3015.

108. Wang, M. S.; Messersmith, R. E.; Reed, S. M., Membrane curvature recognition by C-reactive protein using lipoprotein mimics. Soft Matter 2012, 8 (30), 7909-7918.

109. Orendorff, C. J.; Murphy, C. J., Quantitation of Metal Content in the Silver-Assisted Growth of Gold Nanorods. The Journal of Physical Chemistry B 2006, 110 (9), 3990-3994.

110. Engstrom, A. M.; Faase, R. A.; Marquart, G. W.; Baio, J. E.; Mackiewicz, M. R.; Harper, S. L., Size-Dependent Interactions of Lipid-Coated Gold Nanoparticles: Developing a Better Mechanistic Understanding Through Model Cell Membranes and in vivo Toxicity. International journal of nanomedicine 2020, 15, 4091-4104.

111. Miesen, T. J. E., A. M.; Frost, D.C.; Ajjarapu, R.; Ajjarapu, R.; Nieves Lira, C.; Mackiewicz, M.R. Hybrid Lipid Membrane Coating "Shape-Lock" Silver Nanoparticles to Prevent Surface Oxidation and Silver Ion Dissolution. RSC Advances. 2020, In Press.

112. Engstrom, A. M. W., H.; Mackiewicz, M. R.; Harper, S. L. , Controlling Silver Ion Release of Silver Nanoparticles with Hybrid Lipid Membranes with Long-Chain Hydrophobic Thiol Anchors 
Decreases in vivo Toxicity. International Journal of Engineering Research and Applications 2020, $10,12-28$.

113. Engstrom, A. M. W., H.; Mackiewicz, M. R.; Harper, S. L. (2020) Hybrid lipid-coated silver nanoparticles with long-chain hydrophobic thiol surface coatings show decreased toxicity compared to those without robust surface coatings. International Journal of Engineering Research and Applications. (In Press).

114. Kim, B.-K.; Hwang, G.-B.; Seu, Y.-B.; Choi, J.-S.; Jin, K. S.; Doh, K.-O., DOTAP/DOPE ratio and cell type determine transfection efficiency with DOTAP-liposomes. Biochimica et Biophysica Acta (BBA) - Biomembranes 2015, 1848 (10, Part A), 1996-2001.

115. Qin, C.; Fei, J.; Wang, A.; Yang, Y.; Li, J., Rational assembly of a biointerfaced core@shell nanocomplex towards selective and highly efficient synergistic photothermal/photodynamic therapy. Nanoscale 2015, 7 (47), 20197-210.

116. Miesen, T. J.; Engstrom, A. M.; Frost, D. C.; Ajjarapu, R.; Ajjarapu, R.; Lira, C. N.; Mackiewicz, M. R., A hybrid lipid membrane coating "shape-locks" silver nanoparticles to prevent surface oxidation and silver ion dissolution. RSC Advances 2020, 10 (27), 15677-15693.

117. Xie, X.; Liao, J.; Shao, X.; Li, Q.; Lin, Y., The Effect of shape on Cellular Uptake of Gold Nanoparticles in the forms of Stars, Rods, and Triangles. Sci Rep 2017, 7 (1), 3827-3827.

118. Chandran, P.; Riviere, J. E.; Monteiro-Riviere, N. A., Surface chemistry of gold nanoparticles determines the biocorona composition impacting cellular uptake, toxicity and gene expression profiles in human endothelial cells. Nanotoxicology 2017, 11 (4), 507-519.

119. de Castro, C. E.; Ribeiro, C. A. S.; Alavarse, A. C.; Albuquerque, L. J. C.; da Silva, M. C. C.; Jäger, E.; Surman, F.; Schmidt, V.; Giacomelli, C.; Giacomelli, F. C., Nanoparticle-Cell Interactions: Surface Chemistry Effects on the Cellular Uptake of Biocompatible Block Copolymer Assemblies. Langmuir 2018, 34 (5), 2180-2188.

120. Mekseriwattana, W.; Srisuk, S.; Kriangsaksri, R.; Niamsiri, N.; Prapainop, K., The Impact of Serum Proteins and Surface Chemistry on Magnetic Nanoparticle Colloidal Stability and Cellular Uptake in Breast Cancer Cells. AAPS PharmSciTech 2019, 20 (2), 55.

121. Fröhlich, E., The role of surface charge in cellular uptake and cytotoxicity of medical nanoparticles. International journal of nanomedicine 2012, 7, 5577-91.

122. Yue, Z.-G.; Wei, W.; Lv, P.-P.; Yue, H.; Wang, L.-Y.; Su, Z.-G.; Ma, G.-H., Surface Charge Affects Cellular Uptake and Intracellular Trafficking of Chitosan-Based Nanoparticles. Biomacromolecules 2011, 12 (7), 2440-2446.

123. Jeon, S.; Clavadetscher, J.; Lee, D. K.; Chankeshwara, S. V.; Bradley, M.; Cho, W. S., Surface Charge-Dependent Cellular Uptake of Polystyrene Nanoparticles. Nanomaterials (Basel, Switzerland) 2018, 8 (12).

124. Xia Q, H. J., Feng Q, Chen X, Liu X, Li X, Zhang T, Xiao S, Li H, Zhong Z, Xiao K. Size- and cell type-dependent cellular uptake, cytotoxicity and in vivo distribution of gold nanoparticles. Int J Nanomedicine. 2019;14:6957-6970; https://doi.org/10.2147/IJN.S214008.

125. Kettler, K.; Veltman, K.; van de Meent, D.; van Wezel, A.; Hendriks, A. J., Cellular uptake of nanoparticles as determined by particle properties, experimental conditions, and cell type. Environ Toxicol Chem 2014, 33 (3), 481-92.

126. Foroozandeh, P.; Aziz, A. A., Insight into Cellular Uptake and Intracellular Trafficking of Nanoparticles. Nanoscale Research Letters 2018, 13 (1), 339.

127. Sheedlo, H. J.; Li, L.; Turner, J. E., Photoreceptor cell rescue at early and late RPE-cell transplantation periods during retinal disease in RCS dystrophic rats. Journal of neural transplantation \& plasticity 1991, 2 (1), 55-63. 
128. Silverman, M. S.; Hughes, S. E., Photoreceptor rescue in the RCS rat without pigment epithelium transplantation. Current eye research 1990, 9 (2), 183-91.

129. Skottman H. (2020) RPE and Stem Cell Therapy. In: Klettner A., D. S. e. R. P. E. i. H. a. D. S., Cham.

130. O'Neill, H. C.; Limnios, I. J.; Barnett, N. L., Advancing a Stem Cell Therapy for Age-Related Macular Degeneration. Current Stem Cell Research \& Therapy 2020, 15 (2), 89-97.

131. Koster, C. W., K.E.; Wagstaff, P.E.; van den Hurk, K.T.; Hooijmans, C.R.; Bergen, A.A. A Systematic Review on Transplantation Studies of the Retinal Pigment Epithelium in Animal Models. Int. J. Mol. Sci. 2020, 21, 2719.

132. Isomaa, B.; Reuter, J.; Djupsund, B. M., The subacute and chronic toxicity of cetyltrimethylammonium bromide (CTAB), a cationic surfactant, in the rat. Archives of toxicology 1976, 35 (2), 91-6.

133. Carnovale, C.; Bryant, G.; Shukla, R.; Bansal, V., Identifying Trends in Gold Nanoparticle Toxicity and Uptake: Size, Shape, Capping Ligand, and Biological Corona. ACS Omega 2019, 4 (1), 242-256.

134. Wang, S.; Lu, W.; Tovmachenko, O.; Rai, U. S.; Yu, H.; Ray, P. C., Challenge in understanding size and shape dependent toxicity of gold nanomaterials in human skin keratinocytes. Chemical Physics Letters 2008, 463 (1), 145-149.

135. Albanese, A.; Chan, W. C. W., Effect of Gold Nanoparticle Aggregation on Cell Uptake and Toxicity. ACS Nano 2011, 5 (7), 5478-5489.

136. Durantie, E.; Vanhecke, D.; Rodriguez-Lorenzo, L.; Delhaes, F.; Balog, S.; Septiadi, D.; Bourquin, J.; Petri-Fink, A.; Rothen-Rutishauser, B., Biodistribution of single and aggregated gold nanoparticles exposed to the human lung epithelial tissue barrier at the air-liquid interface. Particle and Fibre Toxicology 2017, 14 (1), 49.

137. Yue, K.; Tang, J.; Tan, H.; Lv, X.; Zhang, X., Nanoparticle Aggregation in Ionic Solutions and Its Effect on Nanoparticle Translocation Across the Cell Membrane. Journal of Heat Transfer 2017, 140 (1).

138. Andreiuk, B.; Reisch, A.; Bernhardt, E.; Klymchenko, A. S., Fighting Aggregation-Caused Quenching and Leakage of Dyes in Fluorescent Polymer Nanoparticles: Universal Role of Counterion. Chemistry - An Asian Journal 2019, 14 (6), 836-846.

139. Wu, P.-C.; Chen, C.-Y.; Chang, C.-W., The fluorescence quenching and aggregation induced emission behaviour of silver nanoclusters labelled on poly(acrylic acid-co-maleic acid). New Journal of Chemistry 2018, 42 (5), 3459-3464.

140. De, S.; Pal, A.; Jana, N. R.; Pal, T., Anion effect in linear silver nanoparticle aggregation as evidenced by efficient fluorescence quenching and SERS enhancement. Journal of Photochemistry and Photobiology A: Chemistry 2000, 131 (1), 111-123.

141. Chen, W.; Tu, X.; Guo, X., Fluorescent gold nanoparticles-based fluorescence sensor for $\mathrm{Cu} 2+$ ions. Chemical Communications 2009, (13), 1736-1738.

142. Walkey, C. D.; Olsen, J. B.; Guo, H.; Emili, A.; Chan, W. C., Nanoparticle size and surface chemistry determine serum protein adsorption and macrophage uptake. J Am Chem Soc 2012, 134 (4), 2139-47.

143. Tedja, R.; Lim, M.; Amal, R.; Marquis, C., Effects of serum adsorption on cellular uptake profile and consequent impact of titanium dioxide nanoparticles on human lung cell lines. ACS Nano 2012, 6 (5), 4083-93.

144. Zhu, X.-M.; Fang, C.; Jia, H.; Huang, Y.; Cheng, C. H. K.; Ko, C.-H.; Chen, Z.; Wang, J.; Wang, Y.-X. J., Cellular uptake behaviour, photothermal therapy performance, and cytotoxicity of gold nanorods with various coatings. Nanoscale 2014, 6 (19), 11462-11472. 
145. Liu, X.; Chen, Y.; Li, H.; Huang, N.; Jin, Q.; Ren, K.; Ji, J., Enhanced Retention and Cellular Uptake of Nanoparticles in Tumors by Controlling Their Aggregation Behavior. ACS Nano 2013, 7 (7), 6244-6257.

146. Moore, T. L.; Urban, D. A.; Rodriguez-Lorenzo, L.; Milosevic, A.; Crippa, F.; Spuch-Calvar, M.; Balog, S.; Rothen-Rutishauser, B.; Lattuada, M.; Petri-Fink, A., Nanoparticle administration method in cell culture alters particle-cell interaction. Sci Rep 2019, 9 (1), 900.

147. Fleischer, C. C.; Payne, C. K., Secondary structure of corona proteins determines the cell surface receptors used by nanoparticles. The journal of physical chemistry. B 2014, 118 (49), 14017-26.

148. Wang, F.; Yu, L.; Monopoli, M. P.; Sandin, P.; Mahon, E.; Salvati, A.; Dawson, K. A., The biomolecular corona is retained during nanoparticle uptake and protects the cells from the damage induced by cationic nanoparticles until degraded in the lysosomes. Nanomedicine: Nanotechnology, Biology and Medicine 2013, 9 (8), 1159-1168.

149. Rampado, R.; Crotti, S.; Caliceti, P.; Pucciarelli, S.; Agostini, M., Recent Advances in Understanding the Protein Corona of Nanoparticles and in the Formulation of "Stealthy" Nanomaterials. Frontiers in bioengineering and biotechnology 2020, 8, 166-166.

150. Almalik, A.; Benabdelkamel, H.; Masood, A.; Alanazi, I. O.; Alradwan, I.; Majrashi, M. A.; Alfadda, A. A.; Alghamdi, W. M.; Alrabiah, H.; Tirelli, N.; Alhasan, A. H., Hyaluronic Acid Coated Chitosan Nanoparticles Reduced the Immunogenicity of the Formed Protein Corona. Sci Rep 2017, 7 (1), 10542.

151. Partikel, K.; Korte, R.; Mulac, D.; Humpf, H. U.; Langer, K., Serum type and concentration both affect the protein-corona composition of PLGA nanoparticles. Beilstein journal of nanotechnology 2019, 10, 1002-1015.

152. Zhu, Z. J.; Posati, T.; Moyano, D. F.; Tang, R.; Yan, B.; Vachet, R. W.; Rotello, V. M., The interplay of monolayer structure and serum protein interactions on the cellular uptake of gold nanoparticles. Small (Weinheim an der Bergstrasse, Germany) 2012, 8 (17), 2659-63. 